\title{
An empirical investigation of expression of multiple entities in Turkish Sign Language (TID): Considering the effects of modality
}

\author{
Inge Zwitserlood ${ }^{\mathrm{a}, \mathrm{c}, *}$, Pamela Perniss ${ }^{\mathrm{b}}$, Aslı Özyürek ${ }^{\mathrm{a}, \mathrm{c}}$ \\ ${ }^{a}$ Radboud University Nijmegen, Nijmegen, Netherlands \\ ${ }^{\mathrm{b}}$ Deafness, Cognition and Language (DCAL) Research Centre, University College London, London, United Kingdom \\ ${ }^{\mathrm{C}}$ Max Planck Institute for Psycholinguistics, Nijmegen, Netherlands
}

Received 5 July 2011; received in revised form 20 August 2012; accepted 21 August 2012

Available online 2 October 2012

\begin{abstract}
This paper explores the expression of multiple entities in Turkish Sign Language (Türk İsaret Dili; TiD), a less well-studied sign language. It aims to provide a comprehensive description of the ways and frequencies in which entity plurality in this language is expressed, both within and outside the noun phrase. We used a corpus that includes both elicited and spontaneous data from native signers. The results reveal that most of the expressions of multiple entities in TiD are iconic, spatial strategies (i.e. localization and spatial plural predicate inflection) none of which, we argue, should be considered as genuine plural marking devices with the main aim of expressing plurality. Instead, the observed devices for localization and predicate inflection allow for a plural interpretation when multiple locations in space are used. Our data do not provide evidence that TiD employs (productive) morphological plural marking (i.e. reduplication) on nouns, in contrast to some other sign languages and many spoken languages. We relate our findings to expression of multiple entities in other signed languages and in spoken languages and discuss these findings in terms of modality effects on expression of multiple entities in human language.
\end{abstract}

(c) 2012 Elsevier B.V. All rights reserved.

Keywords: Sign language; Turkish Sign Language (TiD); Plural; Iconicity; Modality; Language diversity

\section{Introduction}

The concept of singular versus plural is deeply embedded in human cognition. This is reflected in the fact that the distinction is regularly expressed in natural human languages, although not necessarily obligatorily. Spoken languages exhibit much cross-linguistic diversity in the expression of plurality, i.e. in expressing the presence of multiple entities of a type (Corbett, 2000; Dryer, 2011), as is the case for many grammatical phenomena (e.g. Evans and Levinson, 2009). Compared to spoken languages, little is known to date about the expression of multiple entities in sign languages, and in particular cross-linguistically. In order to expand our knowledge on this topic, we explore the expression of multiple entities in a less well-studied sign language, Turkish Sign Language (Türk İşaret Dili; TiD), that is historically unrelated to the (mainly American and European) sign languages that have been more extensively studied. ${ }^{1}$

\footnotetext{
* Corresponding author. Tel.: +31243612052.

E-mail address: i.zwitserlood@let.ru.nl (I. Zwitserlood).

${ }^{1}$ A vastly understudied sign language until recently, research on TiD is fast accumulating. Adding to initial sketches of some historical and general characteristics of TiD (Zeshan, 2002, 2003), and a web-based word list (Özyürek et al., 2004:750 items), there now exist analyses of interrogative and negative constructions (Zeshan, 2006; Gökgöz, 2011), a basic overview of TíD phonology and morphology (Kubuş, 2008), an analysis of verb inflection (Sevinç, 2006), as well as another web-based word list (Boğaziçi Üniversitesi TíD Kaynak Sitesi 2008-2011 [Boğaziçi Üniversitesi TiD Resource Website]; 1327 items). In addition, the expression of spatial relations is discussed in Arık (2008, 2010), Perniss and Özyürek (2008), Özyürek et al. (2010), and Özyürek and Perniss (2011).
} 
The aims of this paper are as follows. The first aim is to provide a detailed description of the various ways in which native TiD signers express multiple entities, both within the nominal domain as well as in syntax, and we discuss the availability, productivity, and obligatoriness of the observed devices for expression of multiple entities in TiD. By using both structured elicited data and spontaneous data from a large data corpus, and by quantifying over the results, we go beyond previous studies on sign language expression of multiple entities.

Second, we aim to compare strategies for multiple entity expression between language modalities, i.e. in spoken and signed language. Particularly we test whether general modality-specific, iconic affordances would predict certain types of such expressions. We propose that the general influence of iconicity accounts for similarities in the expression of multiple entities across sign languages as reported to date, and that TiD behaves consistently in this regard. Overall, the current study thus aims to contribute to our knowledge of the range of possible linguistic expression in this domain as well as to our knowledge about the influence of modality on the expression of the concept of plurality.

The structure of this paper is as follows. Section 2 gives an overview of the ways in which plural reference is expressed in spoken and signed languages. The data collection and analyses are described in Section 3. Sections 4 and 5 detail the results and our analysis of the elicited and spontaneous data sets, respectively. Section 6 discusses the theoretical implications of our results. Our conclusions are in Section 7.

\section{Expression of multiple entities in languages of the world}

Before we move on to the exposition of expression of multiple entities in TiD, we begin with an overview of the different ways in which plural reference is expressed in both modalities. The overview for spoken languages, in Section 2.1, is restricted to the most common and well-known forms due to space limitations (we refer the reader to Corbett (2000) for an excellent treatment). The overview of the means of expression of multiple entities in sign languages in Section 2.2 is based on the few studies that have touched on this domain to date.

\subsection{Expression of multiple entities in spoken languages}

As stated above, spoken languages use a variety of means to mark plurality. Although some languages (e.g. English) distinguish mainly between singular and plural, other languages have special forms for marking two entities (dual), for instance Upper Sorbian (a West Slavonic language), three entities (trial), for instance Larike (a Central Moluccan language used in Ambon Island), and/or some or a few entities (paucal), as in Yimas (a Lower Sepik language spoken in Papua New Guinea), in addition to a general plural form.

Three types of plural marking are generally distinguished: (i) morphological marking on the noun; (ii) lexical marking within the NP but not on the noun; and (iii) syntactic marking. Morphological means of plural marking are diverse and widespread, the most common of them being affixation. Stem change, reduplication, tone, and suppletion are also found on the level of the noun, though they are infrequent, and there is some debate as to whether some of these are in fact morphological processes. A large majority of spoken languages mark plural within the noun phrase $(91 \%$ in a sample of 1066 languages), and especially on the noun, through affixation (60\%), as compiled in Dryer (2011). Table 1 provides some examples. Note that many languages employ two or more plural marking strategies.

Within the noun phrase, plural can be marked lexically by words or clitics that specifically indicate plural. Examples are given in Table 2 below.

Languages may also mark referent plurality through syntactic means, by plural inflection or a plural clitic on verbs and/ or adverbs. ${ }^{2}$ This is illustrated in (1) from Amele (Roberts, 1987:162), where the contrast between singular (1a) and plural (1b) of the object is indicated by the presence of a plural clitic on the verb.
a. Uga jo cehe- i- a
3s house build- 3SG- TODAY'S.PAST.TENSE
'He built a house.'
b. Uga jo ceh- ade- i- a
3s house build- 3p- 3sG- TODAY'S.PAST.TENSE
'He built houses.'

Combinations of plural marking within and outside of the noun phrase are also common. Several plural markers can cooccur within the noun phrase (such as morphological marking on the noun, determiner, and adjectives). Also, plural marking within the noun phrase may combine with plural marking on the verb. This is illustrated in the singular versus

\footnotetext{
${ }^{2}$ Note that this type of plural expression has received far less attention in the literature than plural marking within the noun phrase.
} 
Table 1

Marking of plural on the noun.

\begin{tabular}{llllll}
\hline Type of plural marking & Singular & Plural & Gloss & Language & \\
\hline Affixation & dog & dogs & & English & \\
& iyikwayiwa & wirriyikwayiwa & child & Anindilyakwa & (Leeding, 1989:294 in Dryer, 2011) \\
Stem change & mouse & mice & & English & \\
& nchen & nchiin & older sibling & Maricopa & (Gordon, 1986:29 in Dryer, 2011) \\
(Partial) reduplication & báley & balbáley & town & Pangasinan & (Rubino, 2001:540) \\
& rumah & rumahrumah & house & Indonesian & (Sneddon, 1996:16-17) \\
Tone & màlimò & màlímó & teacher & Ngiti & (Kutsch Lojenga, 1994:135 in Dryer, 2011) \\
Suppletion & person & people & & English & \\
& rebënok & det-i & child & Russian & (Corbett, 2007:8) \\
\hline
\end{tabular}

Table 2

Lexical marking of plural within the noun phrase.

\begin{tabular}{|c|c|c|c|c|}
\hline \multirow{2}{*}{$\frac{\text { Type of plural marking }}{\text { Plural words }}$} & \multicolumn{2}{|c|}{ Plural expression } & \multicolumn{2}{|l|}{ Language } \\
\hline & $\begin{array}{l}\text { aras } \\
\text { horse }\end{array}$ & $\begin{array}{l}\text { nani } \\
\text { PL }\end{array}$ & Miskitu & (Green, 1992 in Corbett, 2000:134) \\
\hline Plural clitic & $\begin{array}{l}\text { me-rišO } \\
\text { PL-new }\end{array}$ & $\begin{array}{l}\text { rab iri } \\
\text { paddle }\end{array}$ & Cayuvava & Key, 1967:50 in Dryer, 2011) \\
\hline
\end{tabular}

plural expressions in (2) and (3). In (2b) from German, plural inflection is shown on the verb as well as with plural suffixes on the noun, the quantifier, and the adjective.

(2) a. Da steh-t ein groß-er Tisch

German

There stand-3P.sg a/one large-sg.m table

'There is a large table there.'

b. Da steh-en einig-e groß-e Tisch-e

There stand-PL some-PL large-PL table-PL

'There are some large tables there.'

Similarly, the Swahili example in (3b) shows plural agreement through the plural noun class marker for humans on the noun, the numeral, as well as on the verb (adapted from Deen, 2005:39).

(3) a. m-toto m-zuri a-me-anguk-a

Swahili

1-child 1-good 1-PR.PERF.-fall-IND

'The good child has fallen.'

b. wa-toto wa-zuri wa-me-anguk-a

2-child 2-good 2-PR.PERF.-fall-IND

'The good children have fallen.'

Plural marking is complex and seldom fully regular or obligatory. For instance, in some languages, plural is only marked on a subset of nouns (e.g. nouns that are high in the animacy hierarchy, particularly nouns referring to humans, as in Australian and North-American languages (Haspelmath, 2011)), or only on nouns occurring in particular contexts, such as first mentions of a referent, topics, or definite nouns (Corbett, 2000). Sometimes plural markers may be used only in particular linguistic environments or constructions. For instance, in Turkish, the presence of a numeral in the subject NP blocks a plural affix on the noun as well as plural inflection on the verb, as illustrated in (4a), whereas plural inflection on the verb is required in case of non-overt expression of the plural referent subject (4b).

(4) a. Sekiz adam-(*lar) Bodrum-a git-ti-(*ler)

Turkish

Eight man-(* $\left.{ }^{*} \mathrm{PL}\right)$ Bodrum-DAT go-PAST- $\left({ }^{*} \mathrm{PL}\right)$

'Eight men have gone to Bodrum.'

b. $\varnothing$ Bodrum-a git-ti-ler

$\varnothing$ Bodrum-DAT gO-PAST-3PL

'(They) have gone to Bodrum.' 


\subsection{Expression of multiple entities in sign languages}

Although relatively few studies have been undertaken with respect to plurality in sign languages to date, several devices for expression of multiple entities have been reported. Like in spoken languages, such devices occur on the referent noun as well as in syntax.

The most-commonly reported means of expression of multiple entities on the noun is reduplication, i.e. one or more repetitions of the referential sign. The sign can be repeated at the same position ('simple reduplication'), or the repetitions may be laterally displaced ('sideward reduplication'). ${ }^{3}$

Another means of expression of multiple entities, particularly for a specific number of entities, involves morphologically complex signs in which a noun is simultaneously combined with a numeral ('numeral incorporation'). This process seems to be restricted to domains of measurement, in particular time (e.g. Frishberg and Gough, 2000). Furthermore, it seems to be constrained to a subset of nouns, i.e. those whose citation form is articulated with an extended finger or thumb, and to numerals up to ten (Liddell, 1996; Mathur and Rathman, 2009, 2010). ${ }^{4}$

Kyle and Woll (1985) mention the possibility of expressing multiple entities by articulating a one-handed sign with two hands ('double articulation') in BSL. ${ }^{5}$ These expressions of multiple entities in the nominal domain are illustrated in Figs. 1-3.

As a lexical means of expression of multiple entities, all sign languages studied to date appear to have numerals and quantifying expressions (as in Figs. 4-5). The use of dedicated plural signs or clitics to mark plural (as for spoken languages in Table 2), however, is not mentioned in the sign language literature.

Finally, various syntactic means for expression of multiple entities are reported for sign languages, primarily pointing signs (including pronouns), classifier predicates, and plural verb inflection. Pronouns in sign languages take the form of pointing signs that are directed towards locations in space associated with (non-) present referents (see McBurney, 2002; Cormier, 2012). Singular pronouns point to individual locations in space, while plural pronouns in many sign languages are typically formed either by multiple points to multiple (individual) referent locations or by a sweeping movement of the index finger to include multiple locations. Furthermore, forms meaning 'the two of us' or 'the three of us' move between two or three locations in space and the number of referents is often expressed by the number of fingers (McBurney, 2002). Some of these pronouns are illustrated in Fig. 6.

Pointing signs can also be used to indicate the spatial configuration of multiple entities by pointing to corresponding locations in sign space. The use of pointing signs for the expression of multiple entities, as illustrated in Fig. 7, is reported for NGT and VGT.

Classifier predicates are morphologically complex predicates in which the classifier refers to a referent. Referents are classified on the basis of salient characteristics like shape (classifiers for long and thin entities, flat entities, and round and/or cylindrical entities are found in almost all sign languages), animacy (some sign languages have special classifiers for humans and animals or for men and women) or other characteristics (e.g. a classifier for vehicles in $\mathrm{ASL}) .{ }^{6}$ Classifier predicates in sign languages function mainly to encode referent location and motion, indicated by the particular placement or movement of the hand in sign space (e.g. Supalla, 1986; Zwitserlood, 2003, 2012; Perniss, 2007). Classifier predicates that are used to encode referent locations are generally expressed with a short movement towards a (usually topographically corresponding) location in space. The classifier itself is expressed by a hand configuration, which is simultaneously expressed with the root in a morphologically complex predicate. Spatial relationships between plural referents are indicated by multiple localizations of classifier predicates in space, as illustrated in Fig. 8.

Multiple entities can also be expressed on other verbs, by modulating their basic shape. For instance, a verb with a single outward movement (as in Fig. 9a below) can be articulated with an outward arc movement to indicate plurality of non-individuated object referents (Fig. 9b), or with repeated movements that are directed to several loci in space to indicate individual plural referents (exhaustive) (Fig. 9c). The use of space in these plural verb inflections is similar to the

\footnotetext{
${ }^{3}$ Reduplication of nouns as a pluralization strategy is reported for American Sign Language (ASL: Wilbur, 1987), German Sign Language (DGS: Pfau and Steinbach, 2006), Hausa Sign Language (HSL: Schmaling, 2000), Israeli Sign Language (ISL: Namir and Schlesinger, 1978; Stavans, 1996), Italian Sign Language (LIS: Pizzuto and Corazza, 1996), TiD (Kubuş, 2008), and Flemish Sign Language (VGT, Heyerick et al., 2011, in preparation). Sideward reduplication has been reported for DGS, LIS, ISL, and VGT.

${ }^{4}$ Numeral incorporation in nouns occurs in ASL (Liddell, 1996), DGS (Mathur and Rathman, 2009, 2010; Perniss, 2001), HSL (Schmaling, 2000), Indo-Pakistani Sign Language (IPSL: Zeshan, 2000), ISL (Stavans, 1996), TiD (Zeshan, 2002) and VGT (Heyerick et al., 2011, in preparation).

${ }^{5}$ This possibility is also mentioned for VGT (Heyerick et al., 2011, in preparation), who claim this form is only used for the expression of two referents.

${ }^{6}$ See Aikhenvald (2000) and Grinevald (2000) for information on classifiers in spoken languages and Zwitserlood (2012) on classifiers in signed languages. See the discussions by Slobin et al. (2003) and Schembri (2003) for discussion of the use of the term 'classifier' for sign languages.
} 
a. DGS

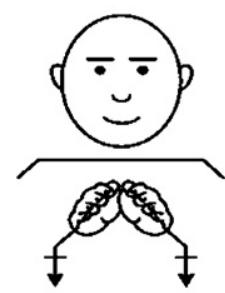

'house'

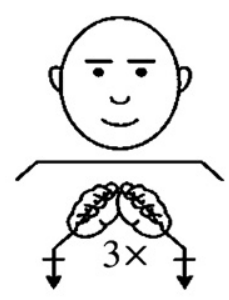

'houses'

b. LIS

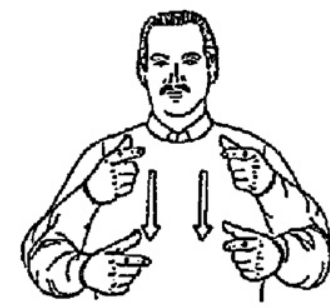

øTOWN

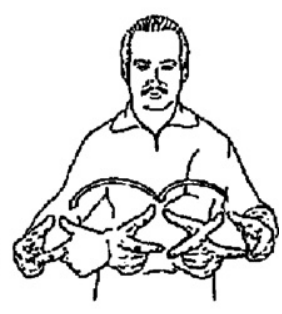

TOWN $\varnothing-\varnothing-\varnothing$

Fig. 1. Expression of multiple entities through reduplication (DGS, Pfau and Steinbach, 2006:146-147; LIS, Pizzuto and Corazza, 1996:176).

a. ASL

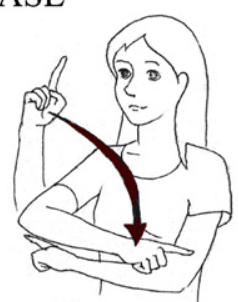

DAY

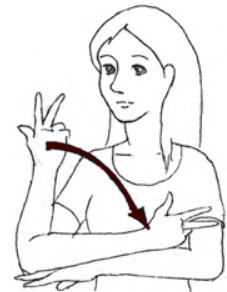

3-DAYS b. DGS

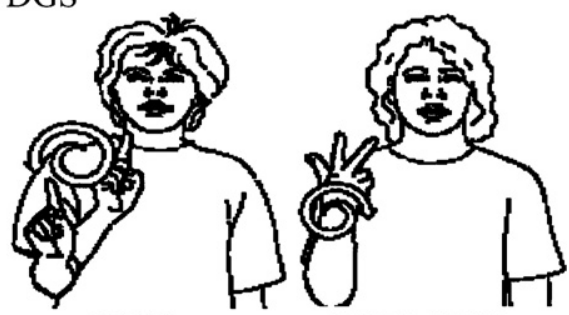

HOUR
THREE-HOUR

Fig. 2. Expression of multiple entities through numeral incorporation (ASL, Fernald and Napoli, 2000:15; DGS).

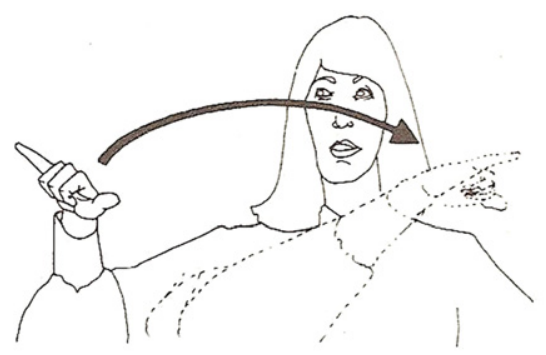

PLANE

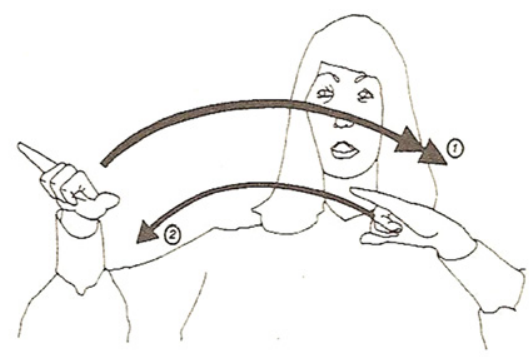

PLANES

Fig. 3. Expression of multiple entities through double articulation (BSL, Kyle and Woll, 1985:133).

spatial modulations found in pronouns for plural referents. Whether verbs can carry inflection of this kind and to what extent a full inflectional paradigm can be articulated, depends in part on their formational properties. In particular, verbs with a place of articulation on or near the body generally tend not to be inflected (Padden, 1988) and inflections that would require awkward bending or twisting of the hand(s) or arm(s) are generally dropped in favor of forms that are easier to articulate (Mathur and Rathman, 2009, 2010). ${ }^{7}$

The use of 'Size and Shape Specifiers' (SASSes; sometimes also called 'Contour Signs' [CS]) is a further means to express multiple entities. These signs trace the outline of an entity and may be located in sign space according to their spatial configuration, similarly to classifier predicates. The literature is equivocal about whether this type of construction involves a morphological or a syntactic process (e.g. Klima and Bellugi, 1979; Nijhof and Zwitserlood, 1999), and about whether their use differs between different sign languages. An example of SASSes to indicate multiple entities in NGT is given in Fig. 10.

Finally, a non-manual device to express multiple entities has been reported to be used in LIS: a repeated, sidewardarticulated head nod accompanying a noun (Pizzuto and Corazza, 1996, no examples provided).

\footnotetext{
${ }^{7}$ See also De Beuzeville et al. (2009) for pragmatic reasons for using or dropping inflection.
} 


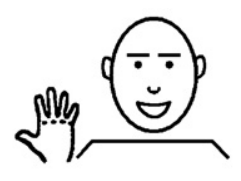

FIVE

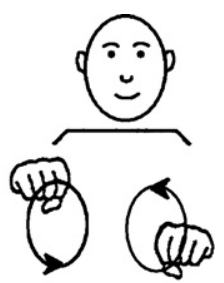

BICYCLE

Fig. 4. Expression of multiple entities with a numeral (Sign Language of the Netherlands [NGT], Nijhof and Zwitserlood, 1999:69).

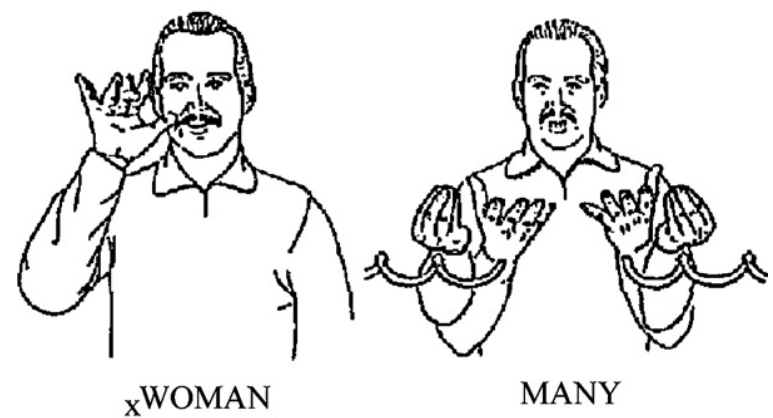

Fig. 5. Expression of multiple entities with a quantifier (LIS, Pizzuto and Corazza, 1996:176).

a.

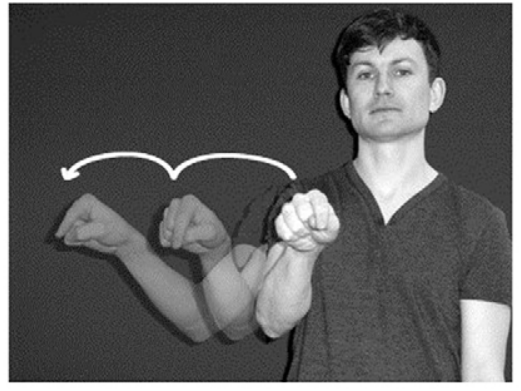

THEY-compositional b.

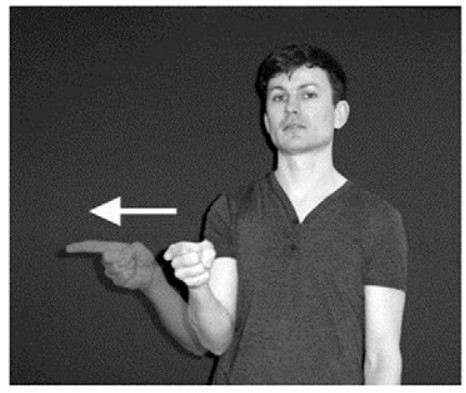

THEY c.

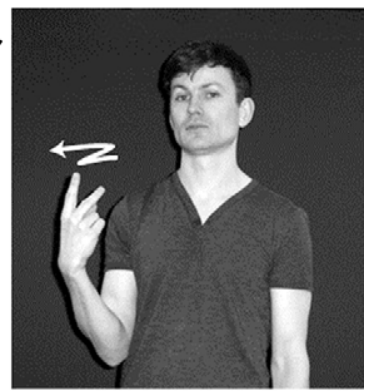

TWO-OF-US

Fig. 6. Pronouns for plural referents (BSL, Cormier, 2012).

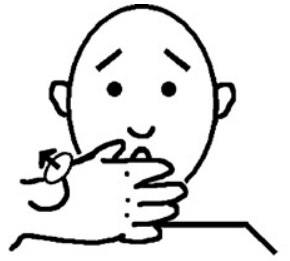

APPLE

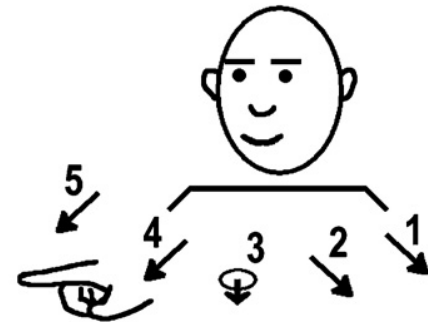

THERE, THERE, THERE...

There are several apples.

Fig. 7. Expression of multiple entities through pointing signs (NGT, Nijhof and Zwitserlood, 1999:70). 
a. NGT
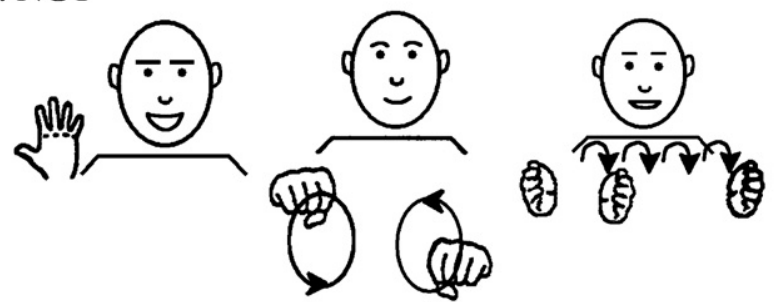

FIVE

BICYCLE

CL $_{\text {BICYCLE}}$-AT SEVERAL
LOCATIONS

There are five bicycles (in a line).

b. DGS
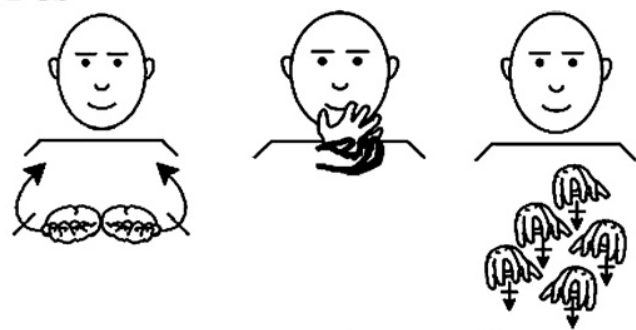

bowl

apple

CL-round-PL

'There are (lots of) apples in the bowl.'

Fig. 8. Syntactic expression of multiple entities through classifier predicates in NGT (Nijhof and Zwitserlood, 1999:69) and DGS (Pfau and Steinbach, 2006:163).

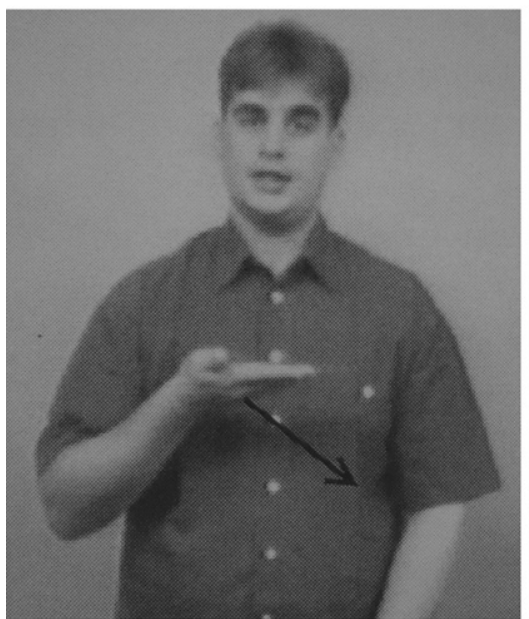

GIVE

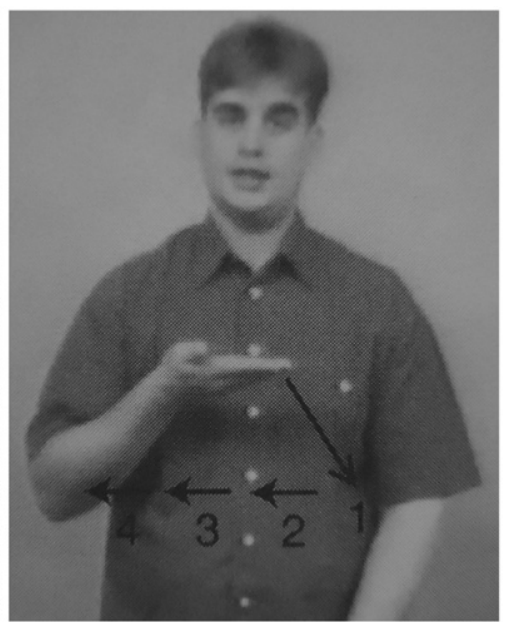

I-GIVE-TO-EACH-OF-THEM

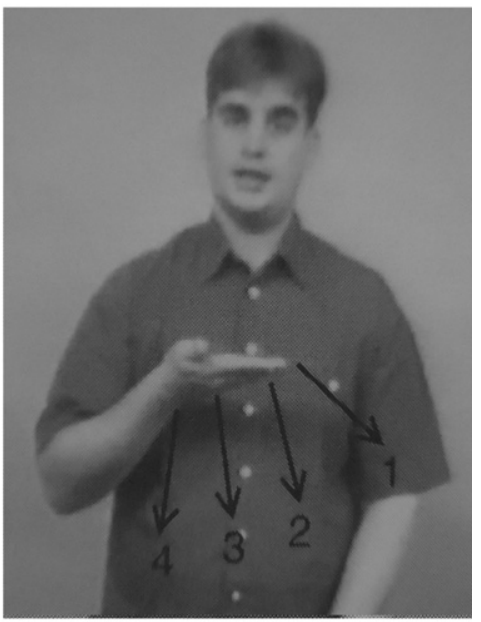

I-GIVE-TO-HER-AND-HER -AND-HER-AND-HER

Fig. 9. Singular (a), plural (b) and plural exhaustive (c) expression through verb inflection (BSL, Sutton-Spence and Woll, 1999:201,142).

\subsection{Synthesis: expression of multiple entities in signed and spoken languages}

Bringing together the literature on both spoken and signed languages we see that similarly to spoken languages, various devices for the expression of multiple entities are found in sign languages in the domains of the noun, the NP, and the verb, and it appears that most sign languages investigated thus far employ several different devices. Pfau and Steinbach (2006:158) claim that the expression of plurality in signed and spoken languages is fundamentally similar, 


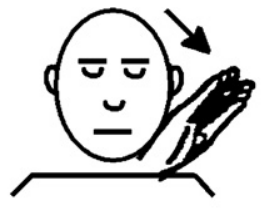

BED
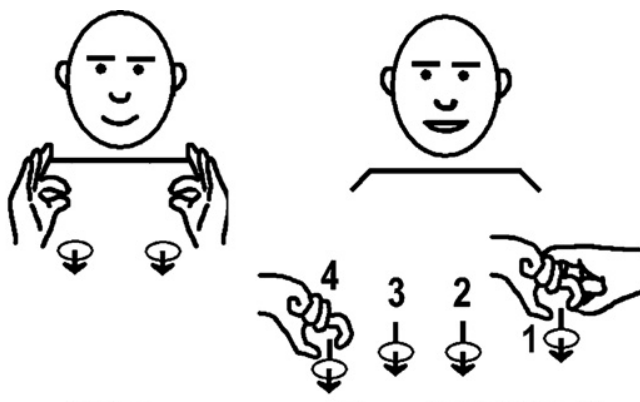

$\mathrm{CS}_{\mathrm{BED}}$-AT SEVERAL LOCATIONS

There's a line of neatly made beds.

Fig. 10. Expression of multiple entities with SASSes (NGT, Nijhof and Zwitserlood, 1999:70).

given that languages in both modalities use the same basic plural marking strategies (specifically, reduplication and zero marking), and that application of these strategies is constrained by phonological properties of the input. However, this claim needs some qualification. First, plural reduplication is not a commonly used plural marking strategy in spoken languages, in contrast to signed languages: it occurs in only $1 \%$ in a sample of 1066 spoken languages (Dryer, 2011). ${ }^{8}$ Pfau and Steinbach (2006) do note that a crucial difference between signed and spoken languages is the absence of plural affixation on the noun (or plural cliticization within the noun phrase) in signed languages. This stands in marked contrast to spoken languages, where these means of plural marking (affixation, in particular) prevail. Sign languages generally disprefer sequential morphology and favor simultaneous, non-concatenative morphology instead (as evidenced in classifier predicates and numeral incorporation, see also Sandler and Lillo-Martin, 2006, and Mathur and Rathman, 2009, 2010). Second, Pfau and Steinbach's claim is restricted to the nominal domain. Most of the reported devices for expression of multiple entities in sign languages, however, go beyond this domain and they make extensive use of space (i.e. classifier predicates, pronouns and pointing signs, spatial verb inflection, and SASSes), which is not available in the aural-oral modality.

It is important to note that not all of the devices for expression of multiple entities in sign languages mentioned above should be considered as genuine linguistic plural markers, i.e. devices with the primary function of expressing plurality. First, numerals and numeral incorporated forms, as well as quantifiers do not qualify as genuine linguistic plural markers, since they do not mark plurality as such but rather indicate a specific number or a general quantity of referents. Second, the use of classifier predicates and other spatially-inflected predicates to indicate referent locations in space does not specifically mark referent plurality: these forms are used for single referents (using a single location) as well as for multiple referents (using multiple locations), with the locations iconically reflecting referent locations in space in both cases. ${ }^{9}$

The picture that emerges is that the particular affordances and constraints of language modality (spoken or signed) substantially shape the expression of multiple entities. Sign languages, in particular, are characterized by a high and pervasive degree of iconicity of the devices used for expression of multiple entities. Specifically, the affordance of iconicity is manifested through the mapping of multiple referents to multiple locations in space and/or to multiple expressions of a (root) form. In concrete terms, the expression of multiple entities in sign languages primarily involves the spatial representation of entities in sign space and reduplication of the noun form (although the number of repetitions does not necessarily match the number of referents).

Thus, it seems that we need more understanding of the way in which modality might shape expression of multiple entities in language in general. Even though the overview in Section 2.2 reflects a good deal of information, our knowledge about expression of multiple entities in sign languages remains fragmentary. So far, the domain has been focally investigated in only a few sign languages. Furthermore, we generally lack a full picture of the devices available and employed in individual sign languages. Some studies have concentrated only on a particular domain (e.g. morphological plural marking on the noun, Pfau and Steinbach, 2006 for DGS), while others have provided information about plural

\footnotetext{
${ }^{8}$ Note, however, that reduplication is a common device for expressing the iterative nature of an event, and occurs productively in many systems of ideophones, mimetics, and other sound-symbolic systems.

${ }^{9}$ We understand that the use of space to indicate the arguments of an inflected verb is not necessarily iconically-motivated (and indeed, much of the literature has assumed that verb inflection uses space in an arbitrary, purely syntactic way, cf. Klima and Bellugi, 1979; Lillo-Martin and Klima, 1990; Padden, 1988). However, even when the spatial modification of sign forms does not reflect a physical spatial arrangement of referents in space, the choice of referent-location associations in space is nevertheless often iconically-motived in that it reflects semantic, conceptual, and pragmatic relations between referents (cf. Engberg-Pedersen, 1993; Liddell, 1998; Mather and Winston, 1998; Van Hoek, 1992).
} 
devices in sketch grammars (e.g. of HSL: Schmaling, 2000), but without indicating whether particular devices are obligatory or productive within the grammar of the particular language. Moreover, detailed information about the structures in which plural devices (co-) occur for different referents and event types and the frequency of certain structures are generally lacking to reach general conclusions about modality effects.

\section{The present study}

To address the above issues we analyze expression of multiple entities in a large corpus with different genres of data of native TiD signers, in two different data sets. One set consists of elicited picture descriptions, where different types of entities (inanimate and non-human animate) are arranged in static configurations. The second set consists of (semi) spontaneous data, where signers related personal narratives to a (deaf) interlocutor, for instance about their families, studies, work, or important events in their lives. This data set comprises various types of events and activities, primarily featuring people as referents. In addition, subsequent to data collection, TiD signers were asked in certain instances to comment on and clarify the use of a specific strategy in a given context. We did not, however, rely on grammaticality judgment tasks since the construction of reliable tasks requires (near) native language skills in addition to thorough linguistic knowledge.

From the elicited data set, we expected the use of classifier predicates as a primary device, since the stimuli depicted multiple referents (inanimates and non-human animates) in spatial configurations. From the spontaneous data set, in which the subjects talked about a variety of subjects and the referents were often humans, we expected the use of inflected predicates as a primary device for expressing plural arguments. Moreover, we expected both data sets to provide contexts in which morphological devices on the noun, (lexical) devices within the NP, and devices occurring on predicates in syntax could be observed as strategies for expression of multiple entities. Our expectations, based on previous research on multiple entity expression in signed languages as well as on the spatial affordances and constraints that have been attributed to the visual-gestural modality (e.g. Meier, 2002; Sandler and Lillo-Martin, 2006), are that TiD will employ iconically-motivated and spatial devices for expression of multiple entities (in particular, those devices described above in terms of syntactic expression of multiple entities), but will make little or no use of affixation or cliticization. On the other hand, non-concatenative morphology may also be expected, and the possibility of non-manual expression of multiple entities (as in LIS) should not be excluded.

\subsection{Data collection and analysis}

In the elicitation task, signers were requested to describe photographs presented to them on a laptop screen. The photographs systematically showed different numbers (one, two, three or four, many) of seven different focal entity types (animate non-human: birds, cows; inanimate: boats, cups, paintings, pens, plates), as shown for cups in Fig. 11. Furthermore, many photographs contained other inanimate entities, occurring in various numbers (chairs, trees, houses, stripes, oars, tiles, stones, colored spots, and flowers). All entities were featured in typical contexts and configurations (e.g. on a table, shelf, wall, street, meadow, water surface). Participants described each picture to a deaf addressee, seated opposite, such that the addressee could select the described picture from sets of 24 thumbnail photographs. If necessary, addressees could ask for repetition or clarification in order to make the correct choice.

In the spontaneous data sessions, participants were asked to introduce themselves and to provide a brief biography and/or to relate one or more notable or memorable events in their lives to another deaf signer. They were free in their choice of event(s).

A total of twenty native adult TiD signers (twelve men and eight women, aged between 20 and 49, mean age 29) participated in this study. Twelve were involved in the elicitation task and fifteen provided spontaneous narratives (seven signers participated in both tasks). All participants are from the region of İzmir.
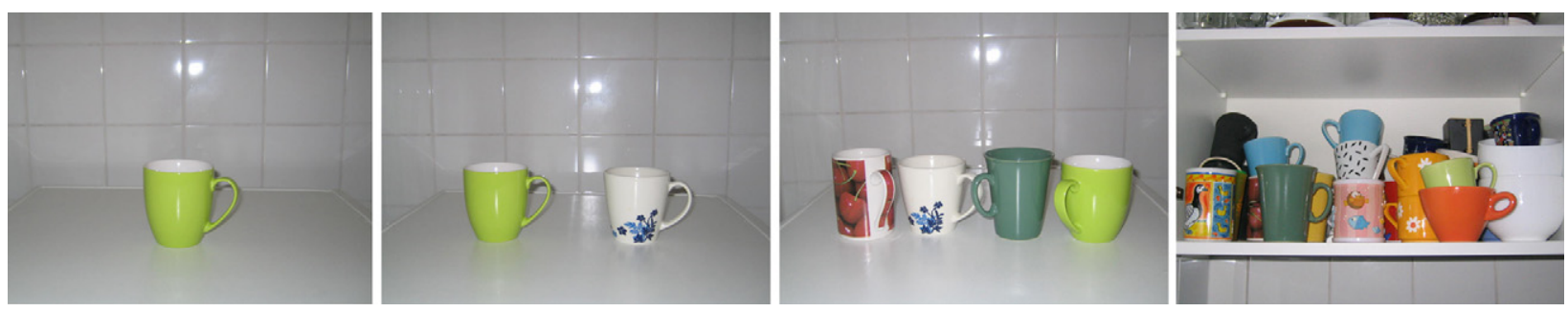

Fig. 11. Examples of stimulus materials. 
In both data sessions, video recordings were made from three different angles: (1) front view of signer, (2) front view of addressee, (3) top view encompassing both signer and addressee. The combination of the front and top view of the signer has proven crucial to ascertaining the use of sign space in what approaches a three-dimensional view.

All data were coded using ELAN, a sophisticated multimedia linguistic annotation tool that allows simultaneous playback of (several) media files, to which annotations can be timeframe-linked. The actions of each of the signers' hands were annotated in glosses in Turkish and English. The Turkish glosses were provided by an assistant who is a native bilingual of Turkish and TiD. Each indication of referent plurality (on nouns and predicates) was coded by a trained linguist in cooperation with a fluent TiD signer. Finally, the types and occurrences of devices for expression of multiple entities were quantified.

It is often difficult to establish the parts of speech in a sign language, as morphological and syntactic clues such as case markers, copulas, and articles are often lacking (e.g. Erlenkamp, 2000; Johnston et al., 2007). Therefore, TiD signs that had a clearly referential function in the context in which they appeared were categorized as 'nouns' and those that conveyed information about states or events with respect to referents were categorized as 'predicates'. We refrained from making finer-grained category distinctions like 'verbs', 'adverbials' or 'adjectives'. We considered all signs that make use of spatial locations to indicate argument(s) as inflected predicates, including directional predicates (i.e. transitive predicates that move between two argument locations) and predicates that are made at the location of (one of) their argument(s).

As explained above, in choosing to collect and analyze two different genres of data, we aimed to target different referent types (i.e. inanimates, animate non-humans, and humans). Of course, the different nature of the data genres elicited and spontaneous - limits the extent to which they are directly comparable. We must take into account that the spontaneous data are less structured, as signers were free in their choice of subject, and therefore, the number of referents and situations that they discussed could not be controlled for. In general, singular entities are much more common in normal language use than plural entities (e.g. three times as frequent in a sample of European spoken languages, Corbett, 2000:285). Thus, in contrast to the elicited data, the spontaneous data is expected to contain comparatively few tokens of expressions of singular and multiple entities of the same referent type.

\section{Results of the elicitation task}

From the 12 participants in this part of the study, we obtained a total of 366 descriptions of the 28 pictures. ${ }^{10}$ There were 273 descriptions of multiple entities: 173 for easily countable entities (two, three, and four) and 100 for many entities. Signers usually described the pictures exhaustively, that is, including the less focal entities in the pictures, such as trees, houses, shelves, tiles, and chairs. 59 descriptions contained a small (i.e. easily countable) number of non-focal entities and 35 descriptions included many (i.e. not easily countable) non-focal entities. Sometimes the participants elaborated on the shape, color, and/or the quantity of the entities (particularly for the focal entities), and typically indicated their location with respect to other entities.

Participants used a range of strategies to indicate multiple entities: numerals, quantifying signs, classifier constructions, noun localizations (i.e. articulations of nouns at locations in sign space), localized signs indicating specific numbers of entities in a side-by-side configuration, localized Size and Shape Specifiers, and spatially inflected predicates to indicate the referents involved in an event. In all responses, participants used at least two strategies, sometimes more than two. We will describe each of these in detail in the following sections, followed by an analysis of the frequency of use of each device.

\subsection{Expression of multiple entities on the noun}

As stated in Section 2.2, three main ways of morphological expression of multiple entities on the noun are reported for sign languages: reduplication, numeral incorporation, and double articulation. ${ }^{11}$ Although it is possible that other devices have developed in different sign languages, we predicted that noun reduplication might well be used as a device for expression of multiple entities in TID because it is a quite frequently reported strategy in other sign languages. Moreover, this strategy was expected since it relies on an iconic mapping (i.e. repetition of the linguistic sign signaling more than one

\footnotetext{
${ }^{10}$ We included multiple descriptions of pictures. Signers often provided more than one description, for instance, when interlocutors asked for clarification. Conversely, due to technical problems, a few descriptions were not recorded properly or were of too poor quality, and were thus not included in the analysis.

${ }^{11}$ We use the term 'reduplication' for sign repetitions with a grammatical function, for instance plural marking or marking of aspect. The term 'repetition' is reserved for forms where repetition does not have such a function, for instance phonologically specified repetitions or phonetic/ prosodic repetitions (following Wilbur, 2005).
} 
a.

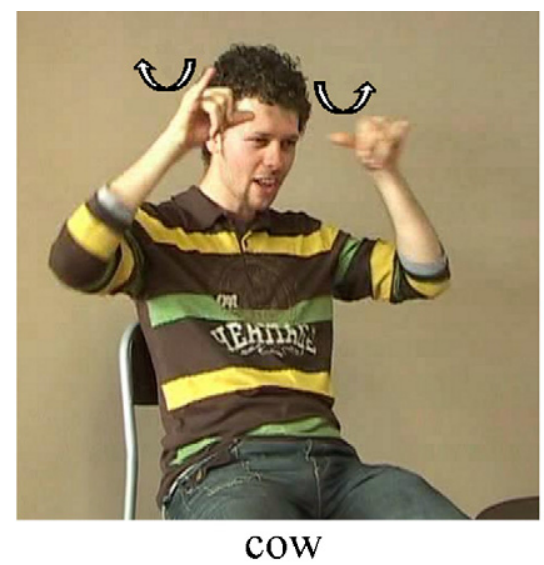

b.

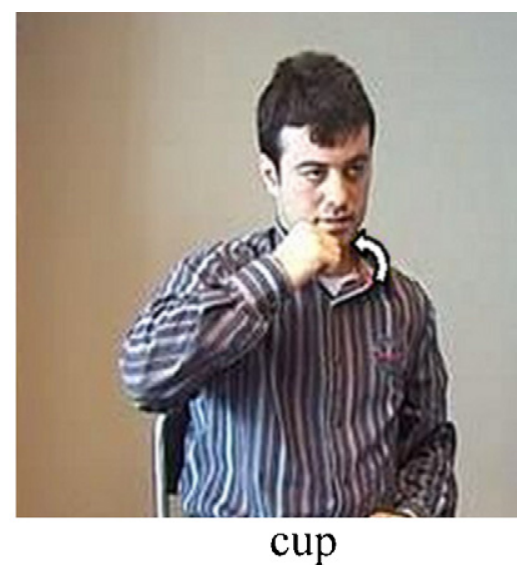

Fig. 12. TiD nouns that are made on or near the body.

entity). Previous literature describes phonological restrictions on the input base for reduplication, i.e. inherent repetition of the sign and articulation of the sign on or near the body blocking reduplication (Pfau and Steinbach, 2006; Pizzuto and Corazza, 1996; Wilbur, 1987), as well as contextual constraints, for instance non co-occurrence of numerals and quantifiers with reduplicated nouns (Pfau and Steinbach, 2006). In order to assess whether these or other restrictions apply in TID, we carefully checked for systematic differences in the articulation of nouns in responses referring to singular entities compared to nouns referring to more than one entity.

First, in the absence of thorough knowledge of TiD phonology, we established the phonological structure of the signs under study. In order to eliminate confusion of phonetic/prosodic context effects and phonological structure of signs as much as possible, we investigated the form of signs in citation form as well as in connected signing (i.e. in the responses to the stimuli). ${ }^{12}$ Then, for a reliable comparison of the nouns in singular and plural contexts, we analyzed the forms of those noun types in our data that occurred with at least two tokens in each context. This resulted in a set of 24 types, with different phonological specifications.

In this set, we did not find systematic noun reduplication to express multiple entities. We did observe a few cases of repeated noun signs in plural contexts, but rule out an interpretation as plural reduplication for the following reasons. First, and crucially, for the same sign, we found no systematic difference in articulation between singular and plural contexts. Second, although plural reduplication might be prohibited by co-occurrence with a numeral or a quantifier within the noun phrase (cf. Pfau and Steinbach, 2006 for DGS, Wilbur, 1987 for ASL, Stavans, 1996 for ISL), we found no difference in the articulation of signs in the presence vs. absence of numerals or quantifiers in our data. Third, phonological restrictions on plural noun reduplication as reported for other sign languages do not appear to be responsible for the lack of plural reduplication on nouns in TiD. Such restrictions are: (i) an input noun with phonological specification for a location on or near the body (e.g. at the forehead) does not allow plural reduplication (Pfau and Steinbach, 2006 for DGS, Pizzuto and Corazza, 1996 for LIS); and (ii) specification for repetition (including alternating movement) in the input noun prohibits plural reduplication, applying in DGS (Pfau and Steinbach, 2006), LIS (Pizzuto and Corazza, 1996), and ASL (Wilbur, 1987). Another, feasible restriction on the manifestation of plural reduplication is that the base must have a movement, i.e. a change in location, orientation, and/or hand configuration in order for reduplication to be expressed.

As stated earlier, our data set included nouns with different phonological specifications. Five out of the total 24 sign types are signs made at a location on or near the body, like the signs for 'cow' and 'cup' in Fig. 12, while 19 signs are not specified for body location and thus produced in the space in front of the signer's body, like the signs for 'boat' and 'tree' in Fig. 13 and 'bird' in Fig. 14. Furthermore, the signs in our data set have different types of movement, i.e. an inherent repeated movement as in the signs for 'duck' and 'bird' in Fig. 14 ( 3 signs), a single, non-repeated movement as in the signs for 'cow', 'cup', 'boat', and 'tree' (18 signs), and no movement ( 3 signs, no example provided).

\footnotetext{
12 Emphasized signs and signs in a prosodic domain-final position typically attract prosodic weight, which can manifest in sign lengthening (i.e. holding the final position of the hand(s)), sign repetition, and addition of 'light' signs (Wilbur and Schick, 1987; Perlmutter, 1992; Van der Kooij and Crasborn, 2008; Crasborn et al., in press). Signs in connected signing may undergo various forms of phonetic reduction, for instance weak drop (articulation of a two-handed sign with one hand: Padden and Perlmutter, 1987) and sign lowering (Schembri et al., 2009; Tyrone and Mauk, 2010).
} 
a.

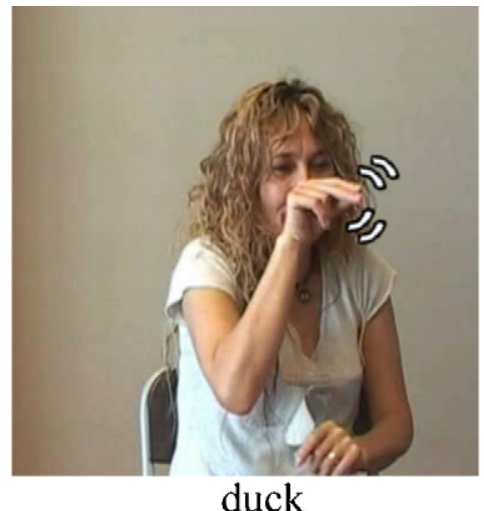

b.

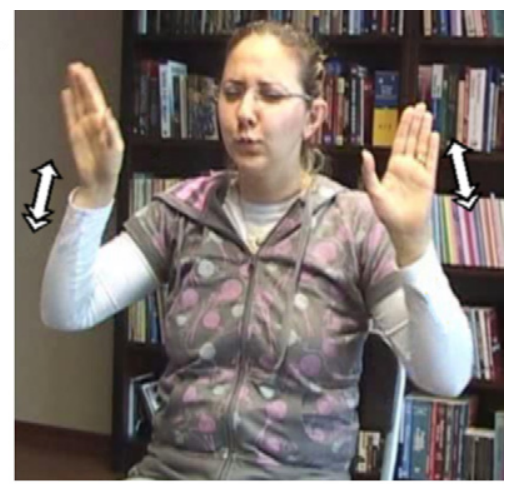

bird

Fig. 13. TiD nouns that are not made on or near the body (with a non-repeated movement).

a.

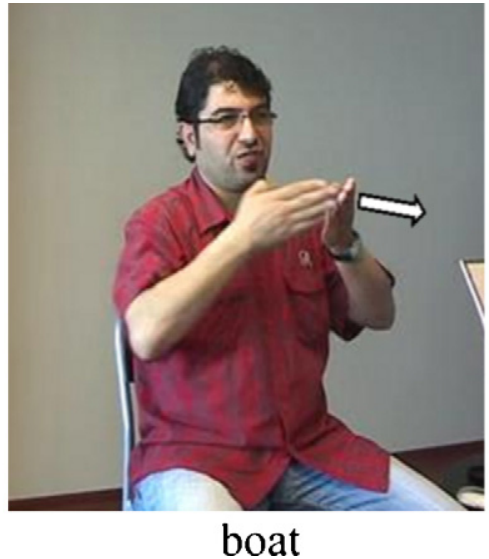

b.

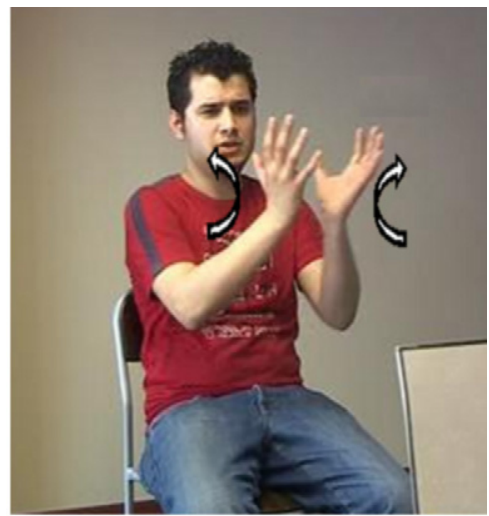

tree

Fig. 14. TiD nouns with an inherent repetition.

However, even the signs that did not occur in combination with quantificational elements and would not be subject to phonological restrictions as in other signed languages (e.g. the signs in Fig. 13) were not systematically repeated in plural contexts. This is illustrated in Fig. 15, where the signer expresses that there are two boats next to each other: the initial sign for 'boat' is not reduplicated.

Note that other restrictions than these may pertain in TiD, since rules and restrictions do not apply equally in different languages. Such restrictions might concern semantic, morphological, or redundancy restrictions (e.g. the presence of two or more devices for expression of multiple entities). These possibilities will be discussed in more detail in Section 5.1.

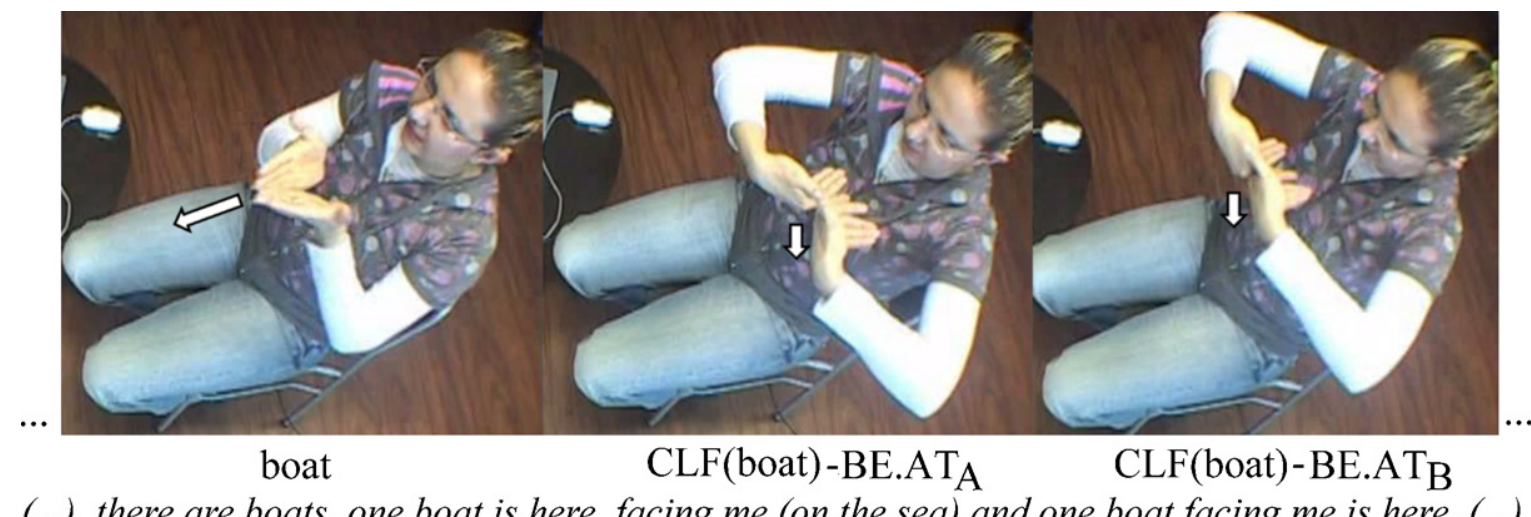

Fig. 15. Non-reduplicated noun in plural context. 
Comparison of nouns in singular and plural contexts showed no other systematic form differences, either. No double articulation, affixation, or changes in the sign form were observed, nor were systematic non-manual markings encountered. In addition, we did not observe numeral incorporation, albeit there may have been little opportunity for this strategy, given that the elicitation task did not include entities that are commonly measured (e.g. time), which are the contexts in which numeral incorporation usually occurs in other signed languages.

\subsection{Numerals and quantifiers}

Like many languages of the world, TiD has several signs that quantify over entities. There is a system of numerals as well as a set of signs that express general quantities of entities, such as signs for 'a few', 'some' and 'many'. Many (though not all) descriptions of stimuli with easily countable entities contained numerals (see the examples in Fig. 16). Quantifying signs, usually those for 'a lot' and 'many', occurred mostly in descriptions of many entities (see the examples in Fig. 17).

It must be noted that the numerals and especially the quantifiers in our data were not always within the same phrase as the noun they modified, as established on the basis of context, word order, intervening material between the noun and numeral or quantifier (including breaks), and prosodic cues (as in Nespor and Sandler, 1999; Sandler, 1999). Numerals and quantifiers sometimes functioned as predicates after mention of the referent noun (comparable to a structure like 'of cows, there are four') or as subjects of a following predicate (e.g. 'of cows, many are walking around'). The difference in

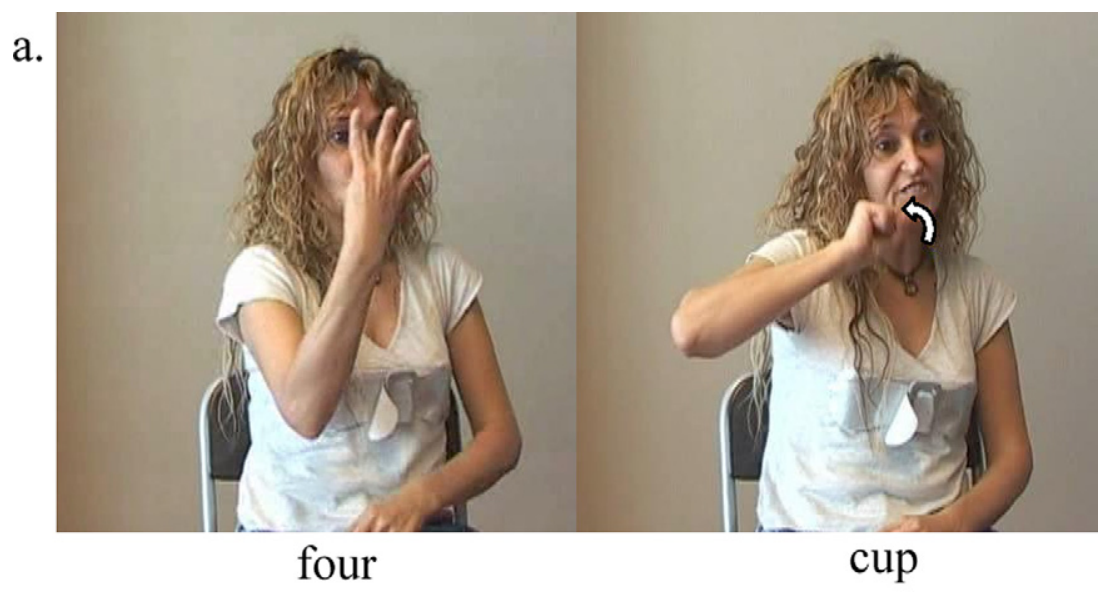

\section{Four cups.}

b.

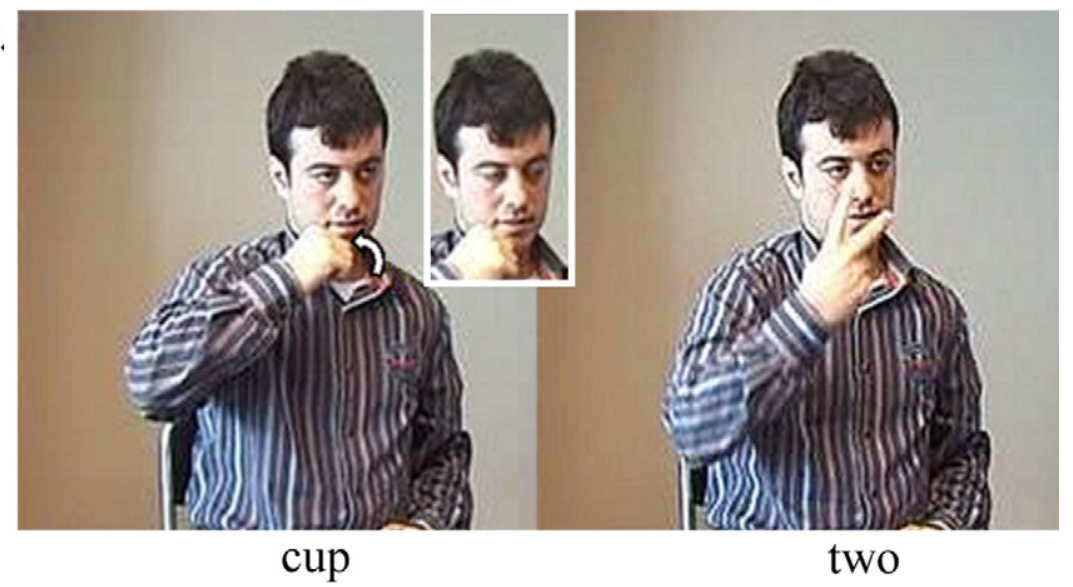

Of cups, there are two.

Fig. 16. Expression of multiple entities through numerals. 


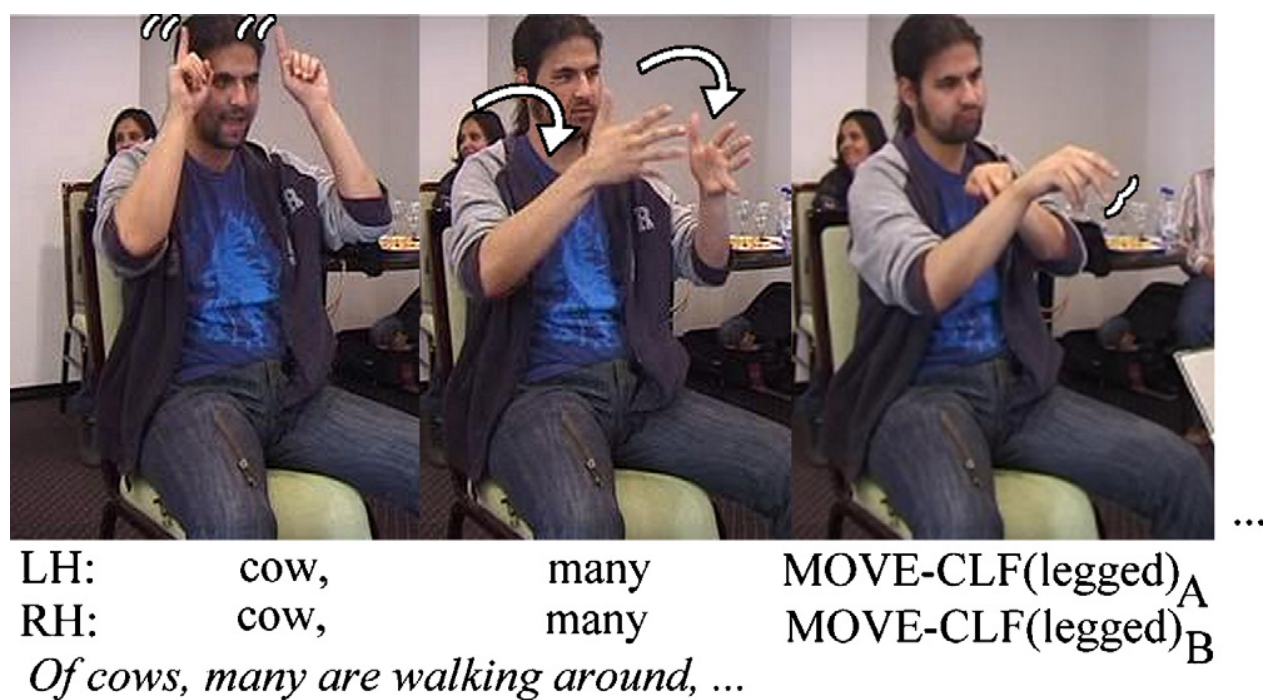

Fig. 17. Expression of multiple entities through a quantifier.

interpretation between Fig. 16a (where the numeral is part of the noun phrase) and Fig. 16b (where the numeral is not part of the noun phrase) is based on the fact that there is a clear prosodic break between the noun and the following numeral in Fig. 16b, i.e. a head nod and an eye blink (as shown in the smaller still between the two signs). Similarly, in the example in Fig. 17, there is a break between the noun and the quantifier. Thus, in these examples, the nouns may serve as topics, that are commented on by the subsequent sign or sign string containing the numeral or quantifier. ${ }^{13}$

Finally, signs or clitics in the noun phrase that specifically encode plural (as described in Section 2.1) did not occur in the data.

\subsection{Expression of multiple entities on predicates}

Participants often expressed multiple entities by localizations in sign space, as expected. For this, they often used classifier constructions, but we also found nouns and SASSes that were articulated at different locations in sign space. Furthermore, a sign indicating a specific number of entities in a side-by-side configuration was encountered, which we have previously described for TiD (Özyürek et al., 2010) but which has not been observed in the same way in any other sign language. We describe each of these below. We analyze all of the localization structures as simultaneous combinations of a localization predicate with another device: a classifier, a noun, a SASS, or a side-by-side configuration.

\subsubsection{Localization of classifiers}

The data contained many instances of localizing predicates expressing the number of referents and their relative locations with a classifier (cf. Kubuş, 2008), both for stimuli in which the entities could be easily counted as well as for stimuli with larger numbers of entities. The classifiers that occurred in our data varied in form and meaning, as summarized in Table 3 below.

In most cases, the finger and/or palm orientation of the classifiers in the descriptions reflected the orientation of the entity in the picture. Examples are shown below. The signer in Fig. 18 indicates an exact number of (two) plates and localizes them by placing two classifiers for flat round entities in the space in front of her (where she has previously localized a table) with a small downward movement.

The signer in Fig. 19 expresses that there are many pictures (on a wall). She uses two hands alternatingly to localize classifiers (for large or bulky entities) on a wall (previously localized in front of her). The separate localizations individuate the entities, although the number of placements of the hands does not represent the exact number of entities (unlike in Fig. 18).

\footnotetext{
${ }^{13}$ A full syntactic analysis of these examples is beyond the scope of this paper. However, they seem similar to quantifier-noun phrase split cases described for ASL (Boster, 1996).
} 
Table 3

Form and meaning of the classifiers found in the TiD data.

Classifier

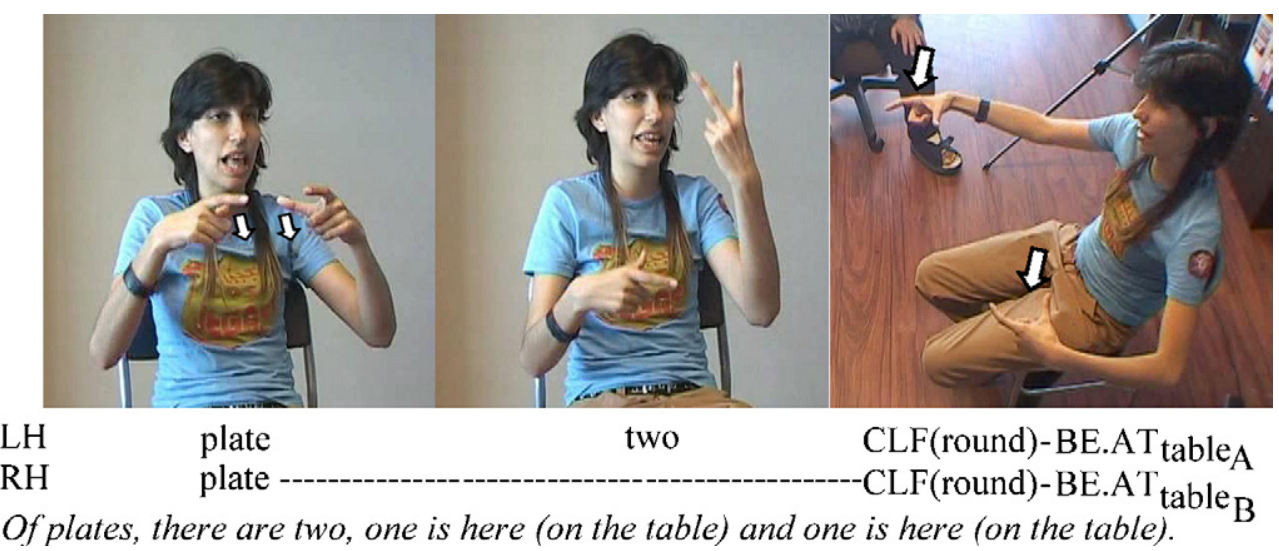

Fig. 18. Representation of the number and locations of referents with classifier predicates.

Localization with classifiers can be done in different ways in TiD (as was also observed by Kubuş, 2008), depending on the number of referents and on whether or not the signer wishes to individuate entities. Sequential one-handed articulations at different locations were generally observed for easily countable entities of the same type. However, for localization of two entities of the same type, a simultaneous two-handed construction, as in Fig. 18, was commonly used (see also Perniss et al., 2011). Repeated localizations with two hands (both simultaneous and alternating) were used for many individuated entities (as in Fig. 19). A 'sweeping' movement through space covering the area in which entities were located was used for non-individuated entities, generally (though not always) for many entities. Straight sweeping movements indicated that entities were in a line. These were repeated at different places to express several rows of entities. Signers also used circular sweeping movements, covering the general area of located entities, as in Fig. 20 below, where the signer indicates that a wall is covered with photos. In our data, the sweeping movements generally occurred with classifiers, but also sometimes with nouns (noun localization will be discussed in Section 4.3.2). ${ }^{14}$

Finally, signers used predicates with numeral incorporated classifiers to localize more than one pen. In contrast to localization of one pen with the classifier for long and thin referents (represented by an extended index finger, see Table 3), signers used forms with two and four extended fingers to localize two and four pens, respectively (i.e. expressing

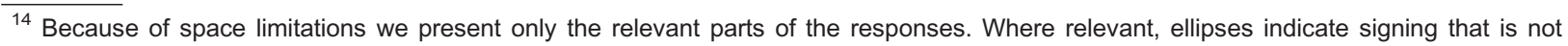
represented in the examples.
} 


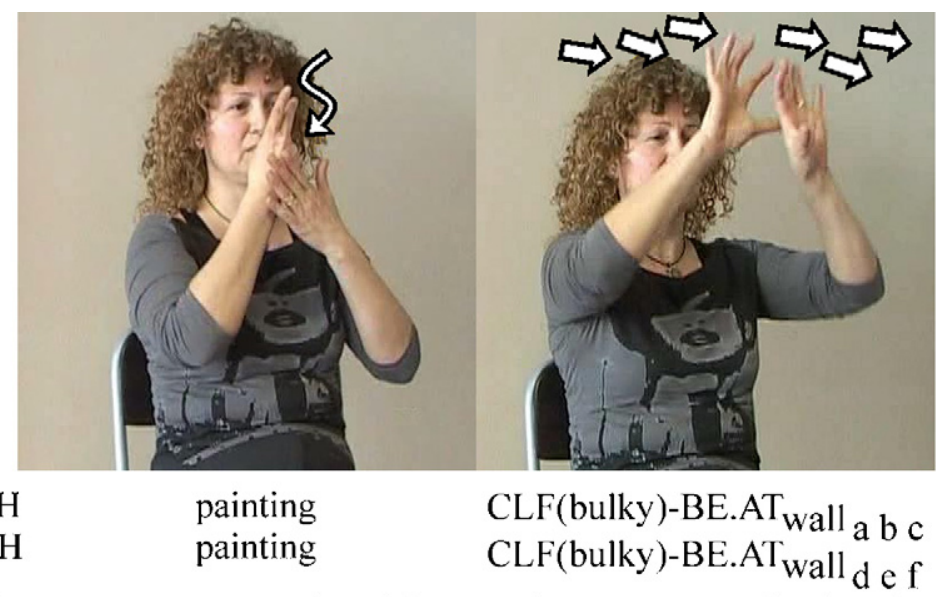

There are paintings, a lot of them are here next to each other (on the wall).

Fig. 19. Representation of many individuated referents and their locations with classifier predicates.

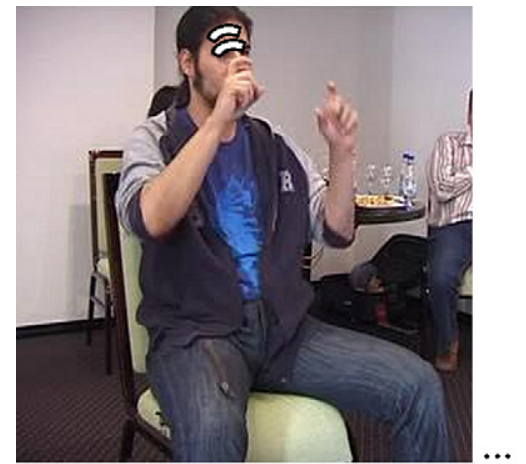

photo

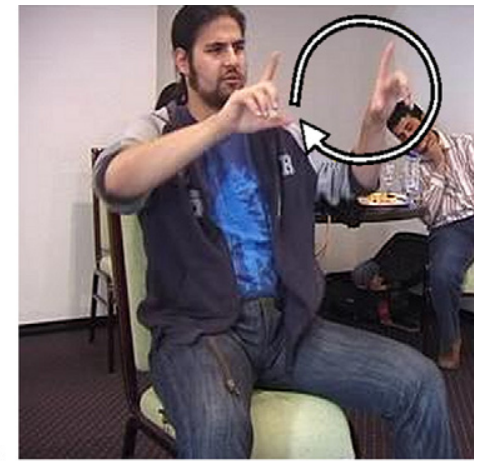

CLF(square)-BE.AT wall

There are photos, (...) covering (the wall).

Fig. 20. Non-individuated expression of many referents and their location using classifier predicates.

the exact number of pens). Similar forms are reported for ASL (Supalla, 1982, 1986), DGS (Perniss et al., 2011), HSL (Schmaling, 2000), and NGT (Zwitserlood, 2003). We will come back to such forms in Sections 4.3.3 and 5.1.

\subsubsection{Localization of nouns}

Localizing predicates were not only combined with classifiers, as described in the previous section, but also with nouns. This is illustrated in Fig. 21 below, for descriptions of pictures with two boats next to each other on the water (Fig. 21a) and three plates next to each other on a table (Fig. 21b). The locations at which the nouns are made in sign space and the number of signs localized clearly reflect the number and the locations of the entities in the stimulus pictures.

Articulation of nouns at different locations in space to express the spatial configuration of referents has also been noted for some other sign languages, for instance DGS (Pfau and Steinbach, 2006) and NGT (Nijhof and Zwitserlood, 1999). Pfau and Steinbach (2006:164-167) analyze such occurrences as marked cases of sideward reduplication that also encode the spatial configuration of the referents. We suggest that these forms should be analyzed as instances of noun localization, i.e. simultaneous combinations of a location root (as in classifier predicates) with a noun, which is possible with nouns that are phonologically underspecified for a location. At times, it was difficult to distinguish (localized) nouns from (localized) classifiers, since some nouns in TiD are expressed by a configuration of the hand(s) only, similar to classifiers, as for instance the sign for 'plate' in Figs. 18 and 21b. We distinguished the use of such forms as nouns or as classifiers on the basis of their distribution and the accompaniment of mouthing. Forms that were used for the introduction of referents were considered nouns, particularly since they were generally accompanied by mouthing of a (part of the) 
a.

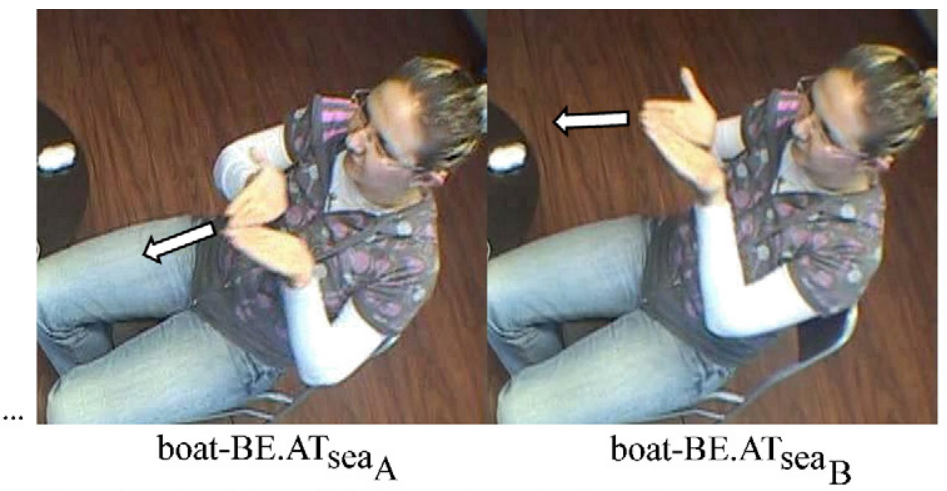

There's a boat here (at the sea) and a boat here.

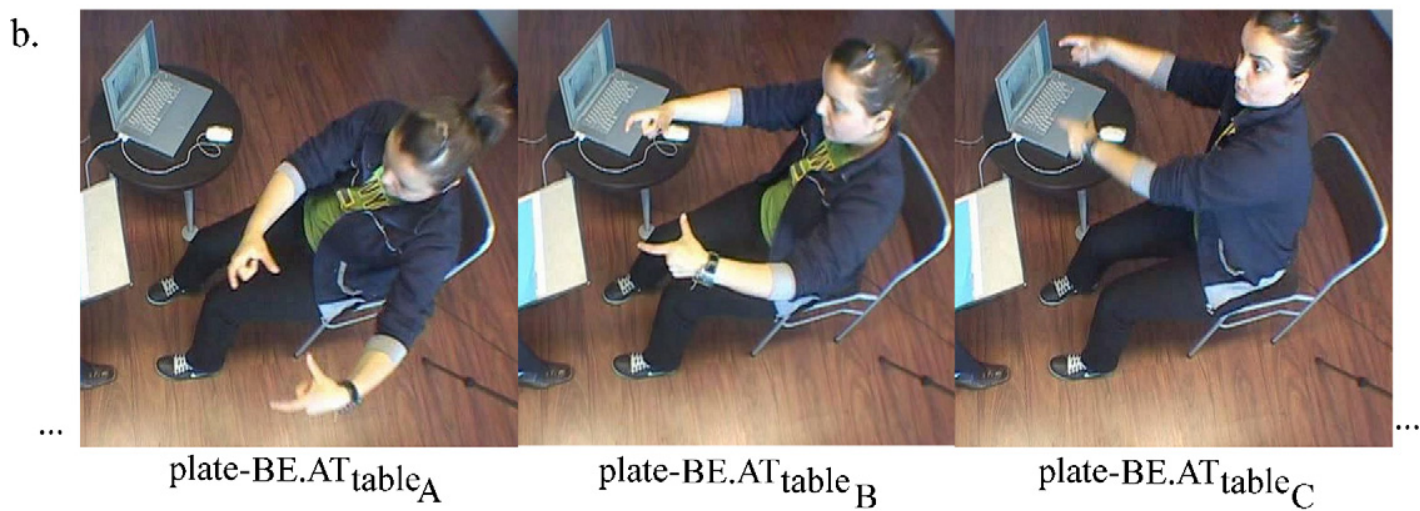

There's a plate here (on the table), a plate here, and a plate here.

Fig. 21. Direct localization of multiple nouns.

Turkish word for the referent (in contrast to classifier localizations). The difference becomes clear when comparing Figs. 18 and 21b. In Fig. 18, the plates are first introduced (accompanied by the mouthing tabak 'plate') and subsequently (simultaneously) localized using classifiers, while in Fig. 21b the sign for plate is immediately localized (with accompanying mouthing of tabak).

\subsubsection{Localization of a 'side-by-side' device for multiple entities}

In addition to the localization strategies discussed in the previous two sections, the TiD signers in our data sample also used a form that we analyze as a localizing predicate combined with a hand configuration that specifically encodes the semantic notion of 'side-by-side'-ness for more than one entity, in the same orientation. This sign type was used by all participants and is illustrated in Fig. 22. The number of extended fingers corresponds to the number of entities next to each other (e.g. four cups in Fig. 22a, and three plates in Fig. 22b). The orientation of the fingers in these examples reflects the upright orientation of the cups and the horizontal orientation of the plates, respectively. The indication of entity orientation is one argument against analysis of these forms as localized numerals, since numerals have a fixed orientation. Rather, they are similar to the numeral incorporated classifier constructions, in which multiple long and thin referents are expressed by multiple extended fingers (as described in Section 4.3.1), and information is provided about the location, orientation, and number of referents. However, the 'side-by-side' forms do not convey any information about the referent's characteristics, in crucial contrast to classifiers. They are used to represent multiple entities of the same (or similar) type in a side-by-side configuration, without restriction on the class or shape of the referents. The sign is used e.g. for multiple pictures, cows, boats, and plates, when these are perceived as being in the same orientation, but never for a single exemplar of these entities. A difference in orientation between a number of the same referent types can be expressed using separate forms in different orientations, as in Fig. 23. (See also Özyürek et al., 2010; Perniss et al., 2011 for a detailed discussion of this construction). 
a.

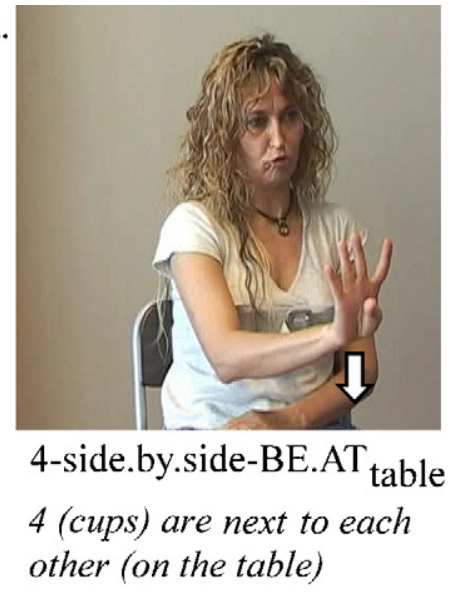

b.

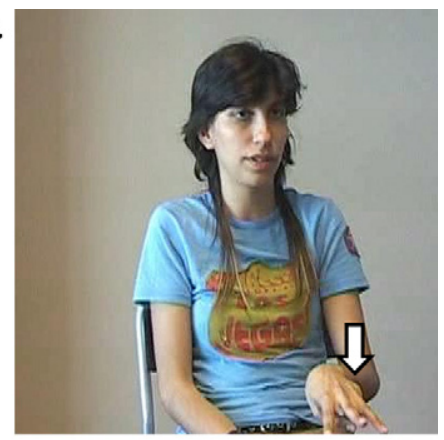

3-side.by.side-BE.AT table

3 (plates) are next to each other (on the table)

Fig. 22. TiD 'side-by-side' localizations.

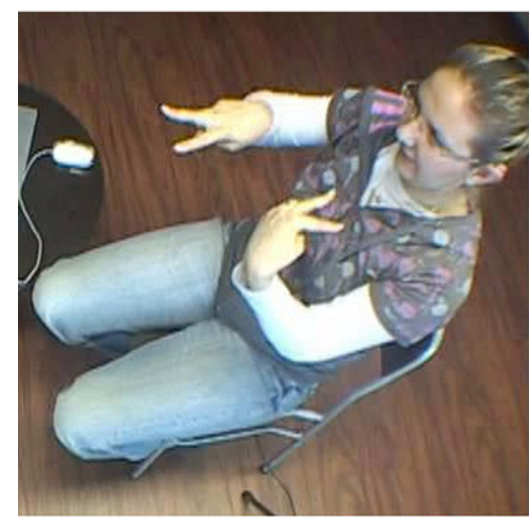
LH: 2-side.by.side-BE.AT water $_{\mathrm{A}}$ $\mathrm{RH}: 2$-side.by.side-BE.AT water $_{\mathrm{B}}$
4 (boats) are next to each other (on the water), 2 are facing me, 2 are facing away.

Fig. 23. 'side-by-side' localizations of entities in different orientations.

\subsubsection{Localization with pointing signs and Size and Shape Specifiers}

In very few cases, signers used pointing signs to locations in sign space to localize multiple entities. More common were localizations of Size and Shape Specifiers (SASS), for instance, to indicate four paintings on a wall, as illustrated in Fig. 24. The signer introduces the referent 'painting' using a lexical sign, and then traces the shape of the paintings at different locations on a wall (that was introduced previously).

\subsubsection{Expression of multiple entities through predicate inflection}

Multiple entities were sometimes expressed through spatial inflection of predicates describing certain properties or activities of the referents. For instance, the signer in Fig. 25 indicates that the two paintings in the stimulus picture are colorful and hanging (on a wall), making the signs for 'colored/colorful' and 'hang' at the locations where the paintings are conceptualized as being (without actually localizing the paintings themselves, e.g. with classifier predicates). Thus, the number of referent(s) is expressed through the articulation of descriptive predicates at the corresponding locations of the referents in space. 


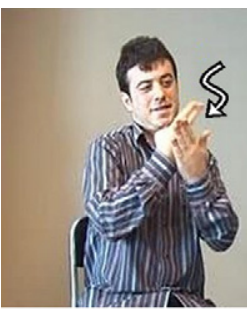

painting

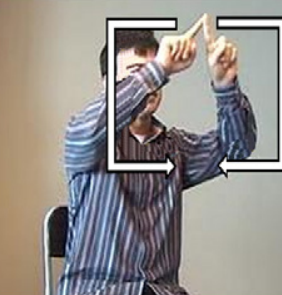

square-BE. $\mathrm{AT}_{\text {wall }_{\mathrm{A}}} \mathrm{squ}$

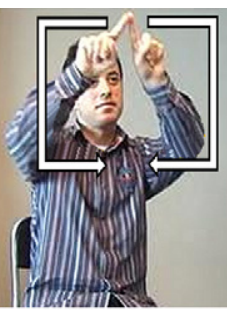

square-BE.AT ${ }_{\text {wall }} \mathrm{B}$

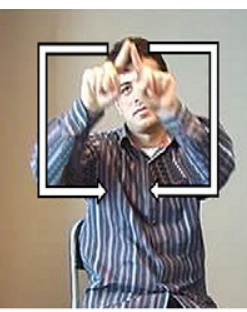

square-BE. $\mathrm{AT}_{\text {wall }}$

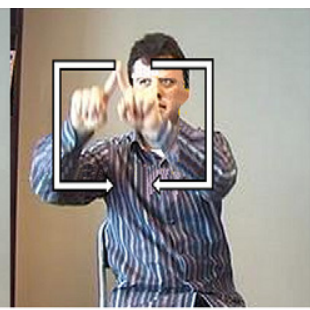

square-BE. $\mathrm{AT}_{\text {wall }_{\mathrm{D}}}$

There are paintings, a square one here, a square one here, a square one here and a square one here (on the wall)

Fig. 24. Localization with Size and Shape Specifiers.

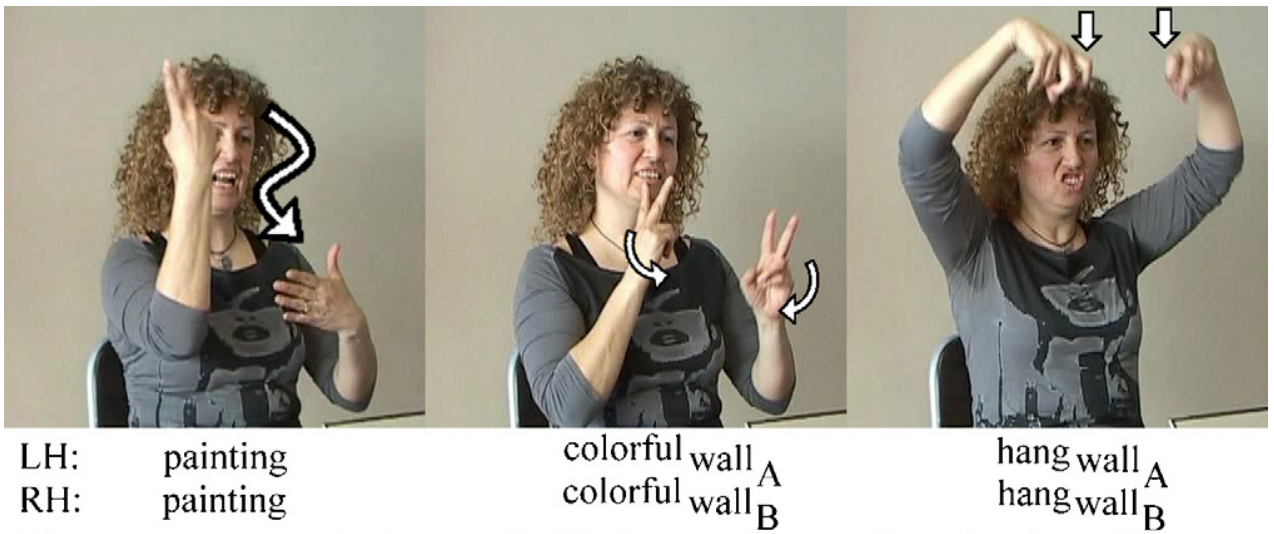

There are paintings, both are colorful, they are hanging here (on the wall).

Fig. 25. Spatial plural predicate inflection.

\subsection{Expression of multiple entities through lexical semantics}

In addition to the devices discussed in the preceding sections, multiple entities were sometimes expressed through the lexical semantics of signs. First, there is a lexical sign that expressly indicates the fact that there are many entities spread out over a surface, as in Fig. 26a (e.g. for many cows in a meadow). We have observed that this sign can, but need not, be localized in space. Note that this sign is different from the classifier predicate with a 'sweeping' motion described in Section 4.3.1. It can be used with all types of entities, regardless of their shape, and the shape of the hands and the movement in this sign is fixed. Another lexical sign that has plurality of entities as part of its lexical semantics is the sign for 'in a bunch'

a.

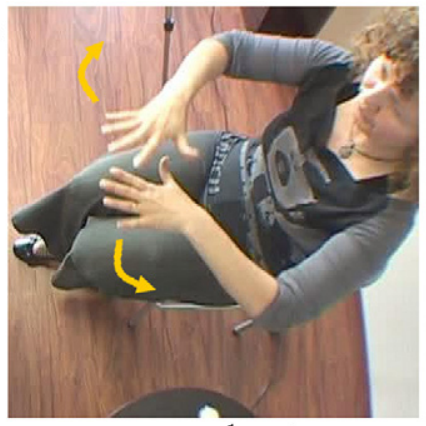

spread-out b.

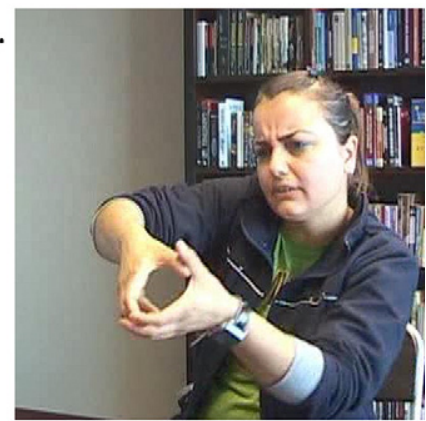

in-a-bunch

Fig. 26. Predicate semantics expressing multiple entities. 


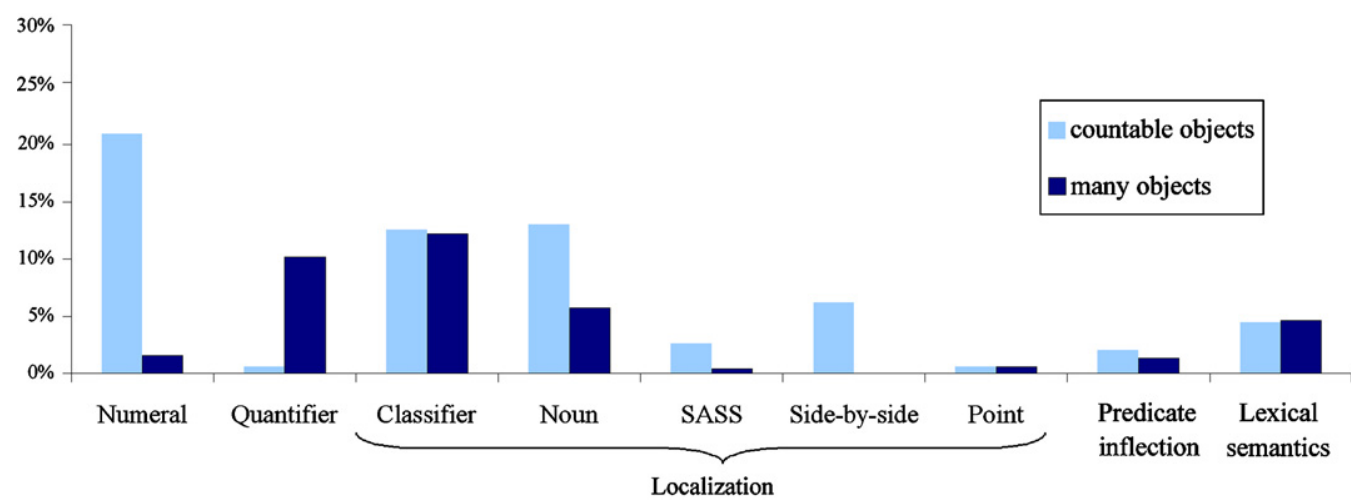

Fig. 27. Distribution of devices used for the expression of multiple entities in the elicited data $(N=645)$ (proportions of all expressions of multiple entities).

(shown in Fig. 26b). ${ }^{15}$ This sign can be used to iconically indicate a bunch of referents. For example, the sign was used in our data set to describe a picture with 'many pens' on a tabletop.

\subsection{Summary}

To summarize our results, concatenative morphological strategies that are typically found in spoken languages (such as affixation and cliticization on nouns) to express multiple entities did not occur in the TiD data. In contrast to what has been found for some sign languages, plural noun reduplication also did not appear to be available in TiD. Nor was any other means of morphological expression of multiple entities on the noun observed. On the other hand, numerals and quantifiers, as lexical expression of multiple entities, were frequently used. Furthermore, signers used sign space for referent localization to indicate multiple entities, making use of the iconic affordances of the modality. Localization, i.e. predication over referents to indicate the referents' locations in space, occurs with classifiers, nouns, and the 'side-byside' sign. Predicate inflection, as described in Section 4.3.5, another spatial strategy (indicating the locations of multiple arguments), occurred sporadically and only when signers chose to focus on properties or activities of multiple referents in the stimuli. Finally, multiple entities were sometimes indicated through the inherent lexical semantics of signs. The distribution of these devices in the elicited data is given in Fig. 27. Overall, spatial strategies, particularly with localizing predicates, are the main devices we found to express multiple entities in static configurations in TiD.

\section{Results of the spontaneous narratives}

As described in Section 3, we also collected and analyzed expressions of multiple entities from (semi) spontaneous use of TiD, i.e. from personal narratives told to another deaf signer. This brings in a different set of referential expressions (including human referents, not present in the elicited data) as well as possible additional devices for expression of multiple entities. The data set consists of $28: 35$ minutes of TiD signing. All referents in the data (overtly and covertly expressed) were coded by a trained linguist in concord with a fluent TiD signer for a singular or plural (or generic) interpretation and were subsequently coded for the devices which yielded this interpretation: morphological, lexical, syntactic, or other(s). In contrast to the elicited data, where several devices to indicate multiple entities were combined within a single description, there was usually only a single indication of entity plurality per instance in the spontaneous data set (and often plural interpretation was left to inference). We discuss the various devices in the sections below.

\subsection{Expression of multiple entities on the noun}

The spontaneous data contained 26 different nouns with a plural interpretation, all different from the nouns in the elicitation task. Parallel to our investigation of expression of multiple entities on the noun in the elicited data, we concentrated on the 12 noun types of which there were at least two tokens in both plural and singular contexts. Three of

\footnotetext{
15 This sign bears similarity to a handling classifier construction (i.e. a sign that indicates holding or manipulation of a bulky entity or a bunch of entities). However, the stimulus pictures did not involve any handling, and did not otherwise elicit handling constructions, thus providing no indication that this form should be analyzed as such.
} 
these types indicated time (days, months, years) and five referred to people (friends, siblings, children, and deaf people). The four remaining noun types referred to both concrete and abstract entities (hearing aids, injuries, ideas, and associations). Again, the phonological specifications of these signs varied (four of the signs are made on or near the body, three have an inherent repetition).

We found no instances of double articulation. Neither did we encounter systematic occurrence of noun repetitions (i.e. reduplication) in plural contexts, corroborating the findings from the elicited data described in Section 4.1. The only exception is found in one of the TID signs for 'child': all five tokens showed sideward reduplication in the context 'two children'. However, rather than morphological plural marking as in some sign languages, this may be a lexical plural form in TiD (as seems to be the case in some other signed languages, for instance IPSL (Zeshan, 2000) and Adamorobe Sign Language (AdaSL; Nyst, 2007)). A few repetitions of nouns were observed in places in the narrative where a signer pondered what to say next and in signs that were emphasized, or at the end of prosodic units (i.e. before breaks, changes in head position, body position, eye gaze direction, and/or facial expression (see Nespor and Sandler, 1999; Van der Kooij et al., 2006)). ${ }^{16}$ These repetitions were found in both singular and plural contexts. Thus, they do not have a morphological function, but rather a prosodic one, and sometimes they are the effect of hesitation during the utterance.

The absence of expression of multiple entities on the nouns in the elicited data could potentially be ascribed to several other factors. However, these factors were not present in the spontaneous data. Results from the elicited data and the spontaneous data with respect to morphological expression of multiple entities on the noun are consistent with each other, so we have grounds to assume that the results have not been influenced by the different tasks. First, the elicited data set comprised mainly concrete nouns for inanimate entities (in addition to some non-human animates), whereas animate, and particularly human, referents are more likely to show plural marking. However, the spontaneous data included nouns for humans and abstract entities in plural contexts, and these did not provide evidence that TiD employs reduplication to express multiple entities for these nouns. This is in confirmation to the findings by Kubuş (2008). Second, the presence of several strategies for expression of multiple entities in one description (e.g. numerals/quantifiers and localizations in space) in the elicited data might have constrained the expression of multiple entities through morphological processes on the noun. However, since multiple entities in the narrative data were expressed by a single device or no device at all (see also Section 5.4), such a constraint does not seem to be at play. ${ }^{17}$

In addition, the spontaneous data contained some instances of simultaneous expression of a noun and a numeral modifying that noun. We will show below that some of these occurrences are instances of numeral incorporation (which corroborates reports by Zeshan (2002) that numeral incorporation is available in TiD), but that the nature of other instances of the simultaneous numeral-noun productions in our data seem rather to reflect a different phenomenon, namely assimilation of the handshape (or: spreading of selected finger features) of an adjacent numeral to that of the noun sign. An example of the latter can be seen in Fig. 28b, where the signer first makes the sign for 'two' (first still) and then articulates the sign for 'year' with two extended fingers (normally signed with one extended index finger as illustrated in Fig. 28a). The simultaneous occurrences of a numeral and the signs for 'year' and 'month' in our data were always adjacent to a separate numeral. (But note that the presence of an adjacent numeral did not necessarily trigger handshape assimilation.) True numeral incorporation, that is not simply the result of handshape assimilation, may be less widespread in actual usage than previously assumed.

The observed instances of true numeral incorporation in our data, as in the expression of school grades ('xth grade') in Fig. 29, lead us to a further new analysis of the nature of numeral incorporation in TiD. Zeshan (2002) and Kubuş (2008) have analyzed numeral incorporation in TiD as simultaneous sign combinations in which the lexically-specified handshape of a particular sign is replaced by the handshape of a numeral. Mathur and Rathmann $(2009,2010)$ adopt a similar view, which they have elaborated on for DGS and ASL. In this analysis, incorporation is only allowed for a subset of (unmarked) handshapes, such as the hand with extended index finger: signs that are specified for a marked handshape cannot be simultaneously combined with another sign that also has a marked handshape feature (i.e. a numeral). If this process and this constraint were also applicable in TiD, we would expect at least the sign for 'year' in our data to show numeral incorporation, being articulated with the same unmarked index finger that allows numeral incorporation in ASL and DGS. However, in order to also account for the occurrence of 'xth grade' expressions, an analysis for numeral incorporation as provided by Liddell (1996) seems more appropriate.

Liddell (1996) suggests that there are bound morphemes in ASL (e.g. roots and prefixes) that do not have full phonological specifications and that combine with numerals between 1 and 9 (e.g. a prefix expressing the concept 'age'

\footnotetext{
${ }_{16}$ This was particularly the case for signs where the hands end in contact with each other or with a body part (see Van der Kooij, 1997), such as the TiD signs for 'year', 'friend', and 'sibling'.

17 Iconic motivatedness of individual sign forms (e.g. the sign for 'boat') in combination with the language's possibility of iconic localization might also influence the likelihood of (simple) reduplication, avoiding the meaning potential of more than one entity at the same location. An in-depth study (which would include iconicity judgment testing of signs) is outside the scope of this study, however, and we leave it for future exploration.
} 
a.

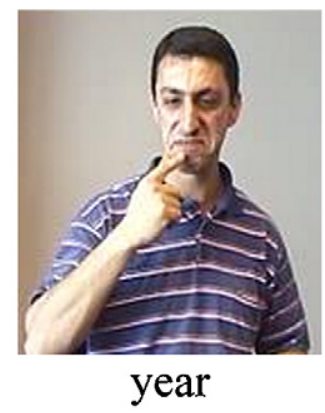

b.

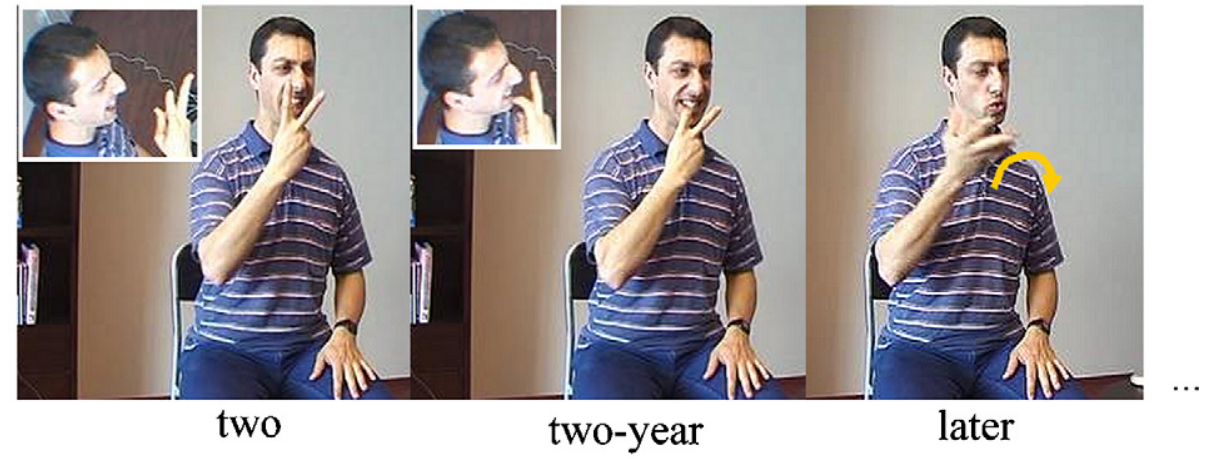

'Two years later...'

Fig. 28. A simultaneous noun-numeral combination.

a.

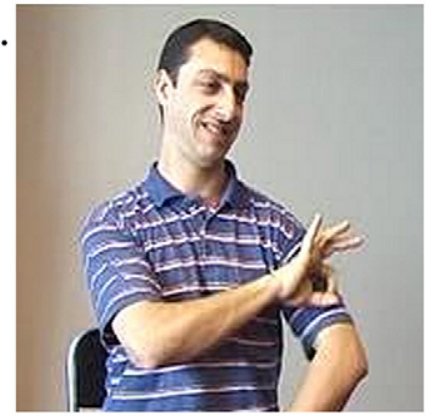

grade 0 b.

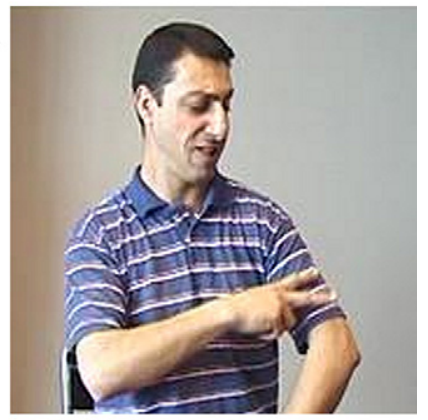

grade 2

Fig. 29. Numeral incorporation in the expression of school grades.

that consists only of a location feature on the chin). Following this analysis of phonological underspecification and simultaneous morpheme combination, we suggest that the TiD expression of 'grade' is phonologically underspecified for handshape features (and only specified for end location feature on the upper arm). Simultaneous combination of this form and a numeral (that is specified for handshape features) is not only possible, but even necessary in order for the sign to be pronounceable (also see Meir, 2001 and Zwitserlood, 2003 for similar analyses of complex signs for Israeli Sign Language [ISL] and NGT respectively). That is, there does not seem to be a citation form that only means 'grade' in TiD; rather, the meaning 'grade' is always simultaneously expressed with a numeral. The same analysis seems appropriate for other TiD signs that show numeral incorporation in our data, such as ' $x$ hundred' and 'in $x$ weeks', as well as for signs reported in Zeshan (2002), e.g. ' $x$ weeks before' and ' $x$ hours'. When used in isolation or in a non-plural context, they have a default singular meaning and combine with the numeral 'one', expressed by an extended index finger. This would mean that these signs are always numeral incorporated (and, thus, morphologically complex), consistent with statements in the literature that 'basic' forms of numeral incorporated signs can be interpreted as ' $1 \mathrm{x}$ ' (Liddell, 1996). It may also explain why other signs articulated with an extended index finger, like 'year' and 'month' do not so readily incorporate numerals: they may, 
indeed, have handshape feature specifications. Instead, these signs exhibit a high propensity for handshape assimilation effects in continuous signing. ${ }^{18}$

In sum, numeral incorporation in TiD seems to be a productive phenomenon, but one that is restricted to elements that are phonologically underspecified for handshape features (as well as the general restriction to signs for units that are commonly measured). Signs that are phonologically specified for extended index finger may in plural contexts also surface with multiple extended fingers, but these are probably cases of handshape assimilation (a phenomenon that is also observed for signs expressed with an extended index finger in ASL, see Liddell and Johnson, 1986 and Sandler, 1996). However, more data is necessary to confirm this analysis.

As for other morphological expressions on the noun, no further indications of multiple entities (such as affixation, cliticization, or mouthing) were observed, neither with nouns referring to inanimate entities nor with nouns for human beings. Overall then, we conclude that TiD does not exhibit productive morphological expression of multiple entities.

\subsection{Numerals, quantifiers, and pronouns}

Numerals were a frequent indication of multiple entities in the spontaneous data. All numerals from 0 to 10 occurred, as well as several numerals between 11 and 30. As in the elicited data, numerals often occurred within noun phrases, preceding the noun, but also sometimes occurred with a predicative function. In addition, some quantifying signs were observed. Furthermore, the spontaneous data contained pronouns expressing plural referents, though infrequently, since referents were very often not overtly expressed. The observed pronouns were either first person plural pronouns (referring to the signer plus one or more others) or non-first person plural pronouns (referring to multiple referents not including the signer). These referents were not physically present in the discourse situation but localized and/or visualized in locations that represented the locations of the referents in the reported event situation. For the first person plural pronouns, forms made with an index finger were used (e.g. 'she and l', Fig. 30a) as well as numeral incorporated forms (e.g. 'the two of us', 'the three of us', Fig. 30b). The (few) non-first person plural forms in the data consisted of a sweeping arc movement and individual pointing signs directed towards the referents. These can be seen in Fig. 30(c-d).

Furthermore, participants frequently used a quantifier with a pronominal function, i.e. the sign for 'everyone', illustrated in Fig. 31.

\subsection{Expression of multiple entities on predicates}

Two devices were encountered in this data set that can be subsumed under plural predicate inflection. First, plural reference was marked by articulating predicates at or directing predicates toward locations in space associated with particular referents. ${ }^{19}$ In Fig. 32a, the signer indicates that three friends were summoned by the protagonist in the narrative by using three different starting locations in space connected to the predicate expressing 'come'. Similarly, the signer in Fig. 32b uses multiple locations in the articulation of the predicates for 'gossip' to indicate the many (individuated) friends at work (colleagues) to whom her friend gossiped about her. (Notice that Fig. 32(a-b) contains nouns referring to multiple friends, but that these nouns are not reduplicated in either example.)

We also observed localizations of a noun sign on different body parts, thus indicating plurality of the referent noun. For instance, a signer indicated that he had three injuries by making the sign for 'injury' once on his leg and twice at locations on his head. We consider this as a special case of expressing multiple entities through noun localization, since body indexicality is involved in interpreting location (Pyers, 2006). That is, locations are interpreted in connection to the relevant body parts through direct indexing of these body parts, in contrast to the context-dependent interpretation of locations in all the previously described cases. It is a general observation that many body parts are referred to in sign languages indexically by pointing to the body part itself. Moreover, some noun signs for referents that are connected to body parts (e.g. hearing devices, spectacles, particular types of clothing) are also made on the relevant body part. Thus, body locations can also be used for expression of (multiple) entities on body parts, provided that the referent nouns are phonologically underspecified for location.

Second, the data contained classifier predicates expressing path movements of plural (human) referents. A classifier expressing 'many (people)' (represented by two hands with extended fingers in horizontal position) moving somewhere was observed most often. This is illustrated in Fig. 33.

\footnotetext{
${ }^{18}$ Note that we do not follow Liddell in assuming that some underspecified signs that incorporate numerals are prefixes. It is more plausible that these signs form the morphological and semantic head of the construction, since the numerals merely modify them.

${ }^{19}$ It should be noted that, as in other sign languages, only a subset of verbs in TiD can be spatially inflected (Sevinç, 2006).
} 
a.

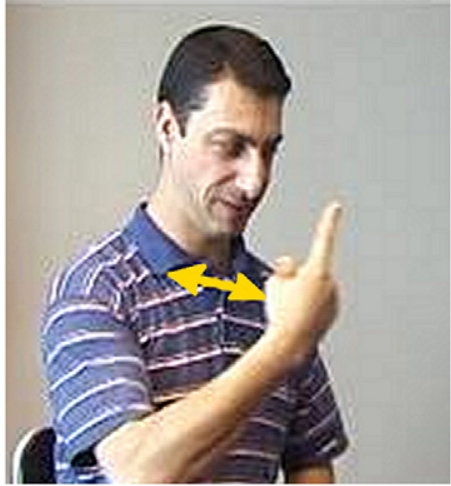

she and I

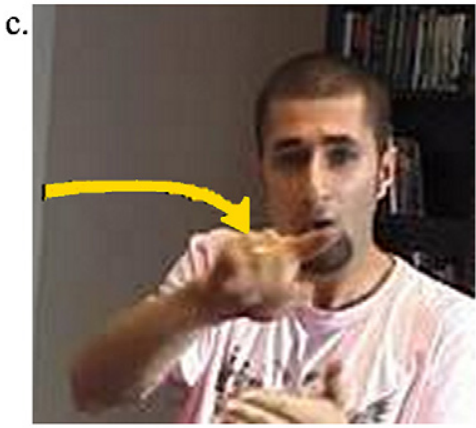

they (all) b.

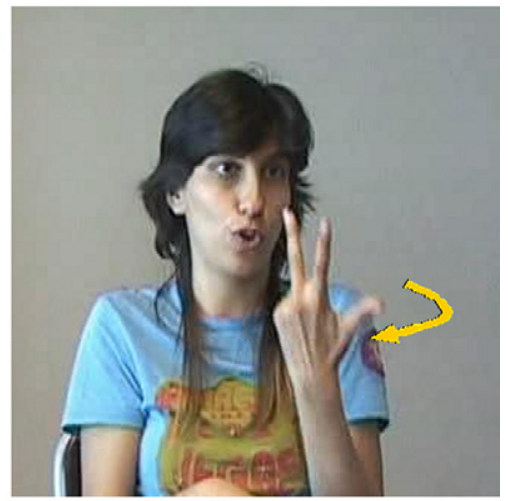

the three of us

d.

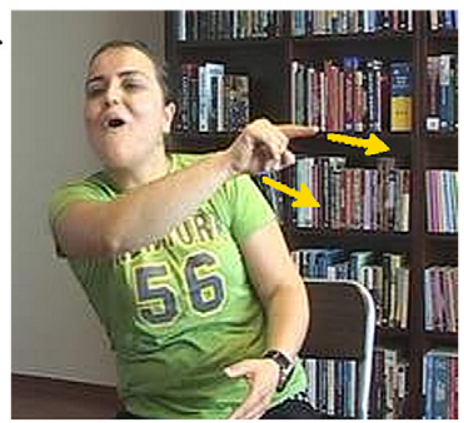

they (each)

Fig. 30. Pronouns for plural referents.

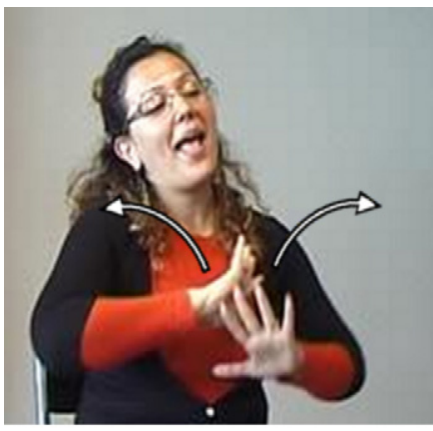

everyone

Fig. 31. Quantifier with pronominal function.

Finally, there were a few instances in which classifiers or nouns were localized in space for plural referent localization. This occurred in contexts in which the static spatial configuration of entities was relevant, similar to the contexts in the elicited data. However, as expected, these contexts were scarce in this data set.

\subsection{Expression of multiple entities through linguistic context}

The spontaneous data include referents with a plural interpretation but without an explicit morphological or syntactic device indicating referent plurality. In some of these cases, a plural interpretation could be recovered from the linguistic (narrative) context. For instance, a signer used the sign for 'sibling' without any marking of plural, translated as: 'I used to live in İzmir with my father, mother and sibling(s).' At the moment of utterance, it is not clear whether the signer had been living together with one or more siblings. Only when the narrative continues with: 'My brother is now married, and my sister moved to Ankara' can it be inferred that the sign for 'sibling' has a plural referent from the fact that the following clauses 
a.

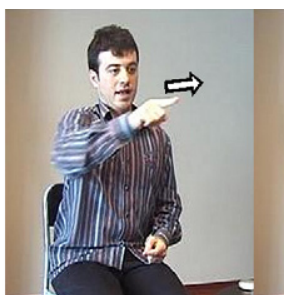

non.1SG

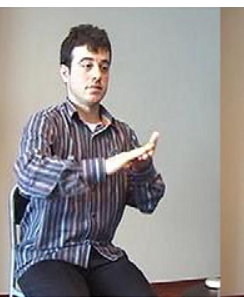

friend

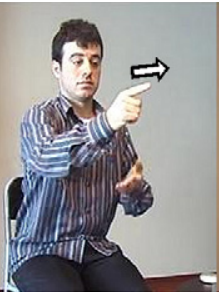

non.1SG

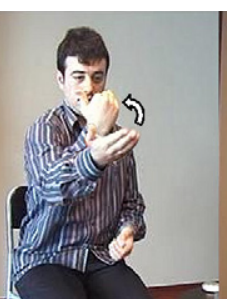

(He said): You, friends, you come here, you come here, and you come here.

b.

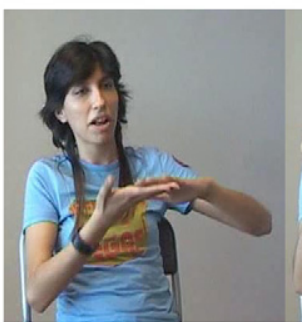

friend

friend

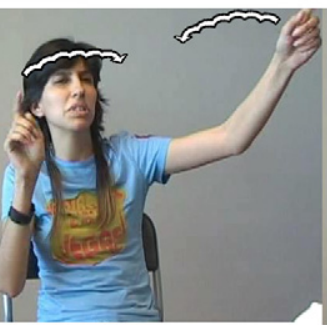

$\operatorname{gossip}_{\mathrm{A}_{\mathrm{a}}} \mathrm{c}$
$\operatorname{gossip}_{\mathrm{A}_{\mathrm{X}} \mathrm{y} \mathrm{z}}$

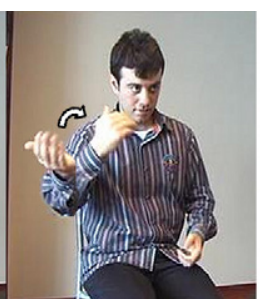

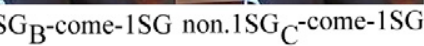

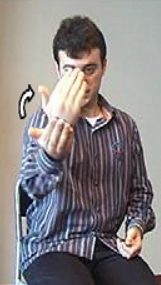

LH

$\mathrm{RH}$

He gossipped to his colleagues at work.

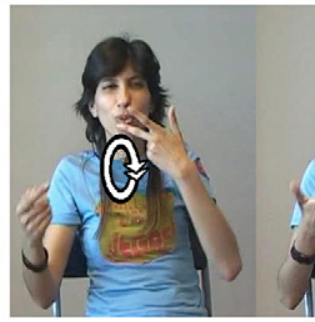

LH

$\mathrm{RH}$

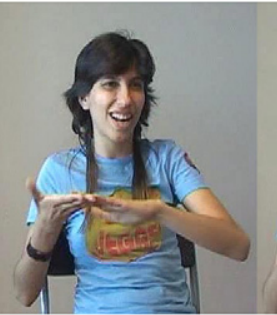

friend $_{B}$

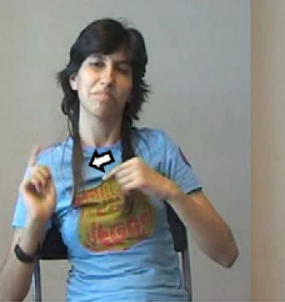

$1 \mathrm{SG}$

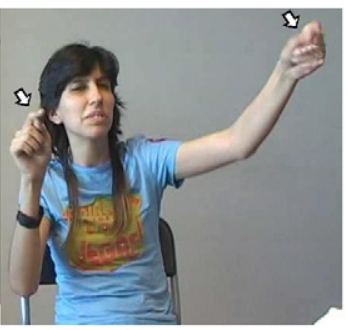

work $\mathrm{A}$

work $_{\mathrm{A}}$

This friend, he gossiped about me with his colleagues.

Fig. 32. Plural predicate inflection.

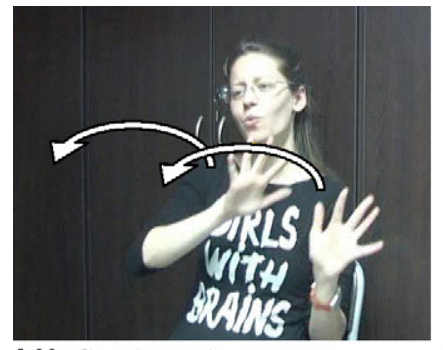

LH: CLF(many)-A move aqua park

$\mathrm{RH}$ : CLF(many)-A move aqua park

(Many people) went (to the Aqua park)

Fig. 33. A classifier predicate indicating many referents moving somewhere. 


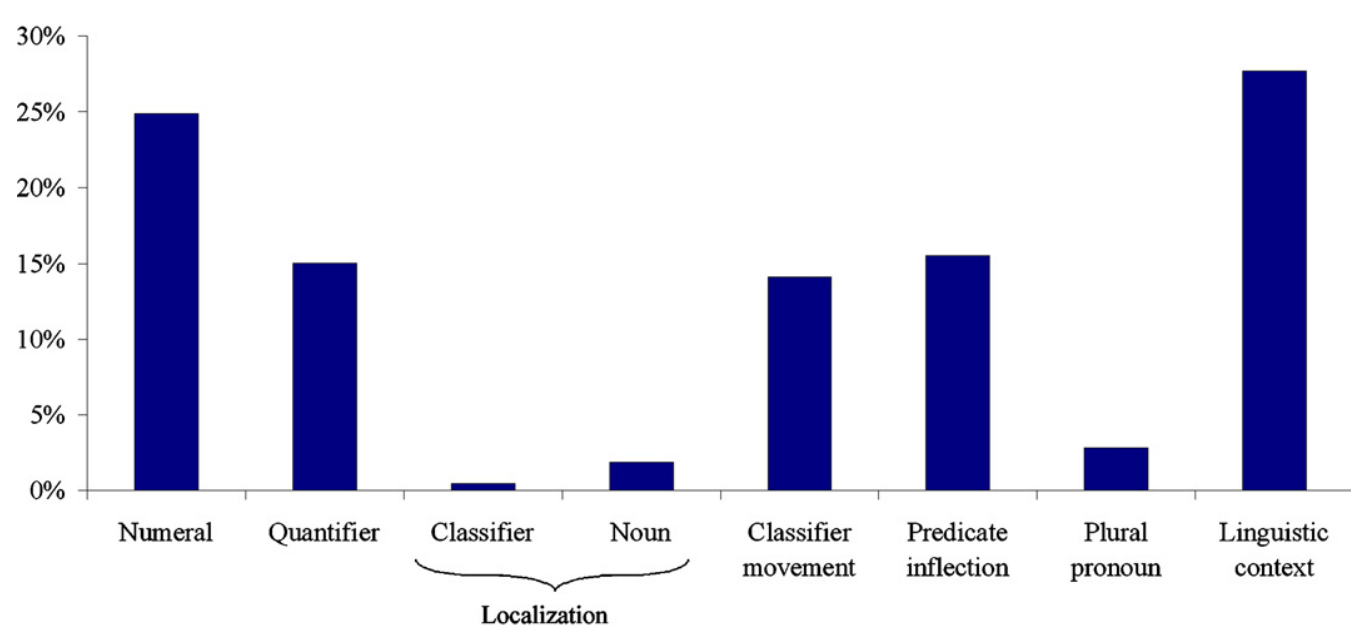

Fig. 34. Distribution of devices used for the expression of multiple entities in the spontaneous data $(N=213)$ (proportions of all expressions of multiple entities).

mention a brother and a sister. Furthermore, some lexical signs (e.g. 'together' and 'other' in the context where first one referent and then one or more other referent(s) were described) imply plural referents, as was also observed in the elicited data.

Still, for a total of 25 referential expressions and ten predicates without overt arguments it remained unclear whether they have a singular or plural interpretation. Thus, singular and plural can be distinguished linguistically, either by specific devices and even combinations of devices, and sometimes through context. In other cases, however, the distinction can be made only on the basis of non-linguistic knowledge, and in some cases, whether referents are singular or plural remains ambiguous and undetermined.

\subsection{Summary}

Similarly to the elicited data, the spontaneous data contained several devices for the expression of multiple entities. Numerals and quantifiers were frequently used devices for indicating multiple entities. Plural inflection and the use of classifier predicates for (human) referents occurred often, but localization strategies (i.e. using localizing predicates) were only sparsely observed. In addition to these devices, a plural interpretation was often implied by the linguistic context. However, like in the elicited data, no productive expression of multiple entities on nouns was observed in the spontaneous data. The distribution of devices for the expression of multiple entities in the spontaneous data is shown in Fig. 34.

\section{Discussion}

\subsection{Implications of the TiD results}

In this paper, we provided detailed descriptions of the expression of multiple entities in TiD. The use of both elicited descriptions of static spatial configurations and spontaneous personal narratives allowed us to cover a wide range of expression in both the nominal and the predicative domain. As a result, we are able to offer a fairly comprehensive description of expression of multiple entities in an individual sign language. Furthermore, we pair our descriptive analysis with a quantificational analysis, and thus offer a first usage-based account of the preferential distribution of the inventory of strategies for expression of multiple entities.

As expected, the different genre types yielded different types of constructions that encoded multiple entities. The elicitation task focused on the expression of multiple entities (inanimate and non-human animate) in static spatial configurations, while the spontaneous narratives focused on events and activities of and between people, and were overall more variable with respect to the specific events described. The elicitation task gave rise to an abundant use of localization predicates, primarily with classifiers, which hardly occurred in the spontaneous data. These, in contrast, offered less opportunity for localization within static scenes. Instead, predicate inflection, spatial motion predicates, and specification within the linguistic context were frequent means of distinguishing multiple from singular referents, which were not common in the elicited data. The observed variation in the strategies for expression of multiple entities shows that 
none of these is obligatory. Each strategy is used to express a particular focus on the state or event, for instance an exact number of entities in case of a numeral and the spatial relation between entities in case of localization and use of a 'sideby-side' device. When signers focused on several aspects of a situation, multiple different devices were used, for instance localization through classifiers, a numeral, and a 'side-by-side' construction. This was particularly the case in the elicitation task, where signers often gave quite elaborate descriptions. Here, signers knew that their interlocutor had the task of selecting the correct picture from an array of pictures, but were unaware of the exact nature of the addressees' materials. In contrast, the spontaneous narratives did not contain the use of multiple devices for the same multiple referent. While being more variable in the strategies for expression of multiple entities, at most one strategy was used at a time, and in many cases, entity number was not explicitly encoded, but rather left to inference.

Overall our results indicate that, in contrast to some other sign languages, TiD does not make use of productive morphological marking on the noun for expression of multiple entities (e.g. reduplication or double articulation). Numeral incorporation appears to be available in TiD (though phonologically and semantically quite restricted), but strictly speaking it is not a plural marking device. Instead, we found that TiD makes use of a wide range of strategies for expression of multiple entities on predicates, some of which have been previously described for other sign languages (e.g. localization with classifiers, noun localization, predicate inflection), but also including some which have not been previously described for TiD or for other sign languages (i.e. the 'side-by-side' device (Fig. 22) and a 'spread' predicate (Fig. 26(a)). In addition, we found that numerals and quantifiers are used in various functions while indicating referent quantity: as modifiers of the noun within the noun phrase, but also predicatively, and as predicate subjects. Finally, there are also contexts in which there is no linguistic indication of whether there is one entity or more, and where this must either be inferred from the context or remains ambiguous.

\subsection{Expression of multiple entities in the visual modality}

We now turn to the role of iconicity, and thereby to the role of the visual modality, in shaping the forms of expression of multiple entities found in TID and the function of iconicity in linguistic structures in TiD, and more generally, across sign languages. The devices for expression of multiple entities on the noun that have been observed in signed languages, i.e. reduplication and double articulation are to a large extent iconic and modality-specific. The principle of 'more of form stands for more of content' (Lakoff and Johnson, 1980) is literally present in noun reduplication in several signed languages. Also, articulation of a sign using two hands simultaneously ('double articulation') iconically represents two entities (Heyerick et al., 2011, in preparation), and this could be considered as another type of reduplication, i.e. simultaneous reduplication. ${ }^{20}$ Furthermore, many of the numerals themselves (particularly the numbers below six and in some signed languages even until ten), occurring independently or as part of a morphologically complex structure, are iconic, representing as many entities. ${ }^{21}$

The most common devices in TID for expressing multiple entities (in particular, localization predicates and plural predicate inflection), that have been observed in most other sign languages, exhibit a high degree of iconicity. Overwhelmingly, the localization strategies, placed in space, map the locations of referent entities in the pictures in an iconic, analogue way. Similarly, with inflected predicates, the use of multiple locations gives an iconic representation of the event configuration, mapping out the presence of multiple referents engaged in an event or activity. As mentioned earlier, localization strategies for multiple referents and predicate inflections cannot be considered to be genuine plural marking devices in sign languages. Their primary function is to localize referents and to mark predicate arguments, respectively. As a result of the use of space and the iconic affordances of the visual modality, these functions are expressed through spatial modification. In the case of more than one referent, multiple referents are associated with multiple locations in space. As such, the expression of plurality comes 'for free', as it were, as an effect of using space for referent localization and predicate inflection.

This pattern holds not only for TiD, as we have shown here, but for sign languages more generally. Given the iconic affordances of the modality, and that entity plurality can be expressed in conjunction with another, primary function (i.e. localization or predicate inflection to mark arguments), we thus go further in claiming that we do not expect that genuine plural marking devices will (rapidly) conventionalize in languages in the visual modality, although it is not excluded in later stages of development of individual languages. Indeed, it seems that the only such genuine plural marking device in sign languages found to date is noun reduplication, which has been reported to be used in many sign languages (ASL, DGS, HSL, ISL, LIS, and VGT). However, various other sign languages do not exhibit noun reduplication as a strategy for

\footnotetext{
20 Thanks to an anonymous reviewer for suggesting this analysis of double articulation.

${ }^{21}$ It is suggested that the numerals in TiD from 7 to 9 are iconic representations of the shape of these numerals in Western Arabic notation, that was used before the Western orthography and numeral system was adopted in Turkey (Hasan Dikyuva, pc. Sign5 Conference Ankara, October 21, 2011).
} 
expression of multiple entities (AdaSL, IPSL, NGT, and TiD), and even in those sign languages where it does occur, it is discussed as being quite restricted-dependent on the phonological properties of sign forms (Pfau and Steinbach, 2006; Pizzuto and Corazza, 1996; Wilbur, 1987) and the linguistic context, i.e. presence or absence of a numeral or quantifier in the noun phrase (Pfau and Steinbach, 2006). Importantly, none of the previous studies has shown to what extent the process of noun reduplication is productive for nouns that do not exhibit such constraints.

In contrast, referent localization (in particular localization with classifiers) and predicate inflection (indicating the referents involved in an event) are widespread, and are similarly structured across many sign languages. In line with what we are arguing here, their structure is generally described in terms of modality effects, afforded by the iconic and spatial properties of the visual-spatial modality. We thus clearly distinguish genuine plural marking devices (e.g. noun reduplication) from those devices which have a different main function (i.e. to depict a spatial configuration or to mark predicate arguments), but which express information about referent number as a result of their spatial modification and iconic motivation. Note that noun reduplication is also an iconic strategy, using repetition of a sign form to indicate more than one referent. As such, even the prominent genuine plural marking strategy used in sign languages relies on iconic mapping to a high degree.

\subsection{Modality-specific effects: sign versus spoken languages}

When we consider expression of multiple entities in sign languages compared to spoken languages, we can argue for a modality-dependent nature of expression in a number of respects. Sign languages overall reveal less diversity in this domain than spoken languages (reviewed in Section 2.1). Also unlike spoken languages, which exhibit a high degree of plural marking on the noun through affixation (60\% of languages in Dryer (2011)'s sample), sign languages seem never to use affixation for plural marking, and even generally do not seem to prefer plural marking on the noun. Instead, plurality of entities is preferentially expressed outside of the noun phrase by means of localization predicates and/or inflected predicates. A similarity between signed and spoken languages, however, is that referent plurality may often remain unexpressed, showing the importance of pragmatics and contextual dependence in language, in general (cf. Corbett, 2000; Evans and Levinson, 2009).

The visual modality allows for structures that are impossible in any spoken language due to the fact that the oral modality is by and large restricted to a linear, one-dimensional signal and only has one articulator at its disposal. Thus, double articulation structures (i.e. equivalents of lexical signs made on each hand simultaneous or of simultaneous bimanual localizations, as described in Section 4.3.1) are not possible. Similarly, although spoken languages do employ non-concatenative morphology to some extent (e.g. Semitic and Hebrew languages, see also Mathur and Rathman, 2010 and Sandler and Lillo-Martin, 2006 for comparison), simultaneous realization of morphemes as in numeral incorporation seems a typical feature of signed languages.

The iconic nature of many devices for expression of multiple entities in sign languages has been discussed in detail. Yet, in spoken languages, too, the expression of multiple entities is to some extent iconic in nature in that it involves adding material to a singular form ('more of form stands for more of content', Lakoff and Johnson, 1980:128). However, apart from plural reduplication ('more of the same'), the form that this additional material takes in spoken languages (i.e. affixes, clitics, and plural words) is not itself iconic of the (multiple) entities.

With respect to reduplication, another implication of the modality is that signed languages do not seem to employ partial reduplication, in contrast to spoken languages. Reduplication in signed languages shows at least one full repetition (albeit the size of the repeated movement is often reduced, consistent with phonetic weight reduction effects, see Crasborn et al., 2012). The full repetition seems to result from the favored monosyllabicity of signs and the modality-specific simultaneous expression of phonological features within the syllable. ${ }^{22}$

It has been suggested that the structural similarities across sign languages compared to the diversity of spoken languages may be a result of the relative youth of sign languages, with the implication that sign languages may grow more diverse over time (e.g. Aronoff et al., 2005; Meier, 2002; Sandler and Lillo-Martin, 2006). ${ }^{23}$ However, differences between sign languages may exist at deeper levels than have been explored thus far and discovering them requires study of many sign languages and using large corpora. This study contributes to this by the use of a corpus of elicited and spontaneous data of a large number of participants, its combination of description and analysis, as well as its quantification over the results.

\footnotetext{
22 DGS is even reported to show plural 'triplication', i.e. the signs are repeated twice (Pfau and Steinbach, 2006, illustrated in Fig. 1), although one repetition is also common in DGS (Perniss, 2001).

${ }^{23}$ Suggestions that Turkish Sign Language dates back more than 500 years and descends from the signed language used in the Ottoman courts cannot be verified due to a lack of (language) sources (Zeshan, 2002).
} 
Our study still has its limitations in that only a restricted set of nouns expressing plural referents was studied, and no systematic comparison of the linguistic environments in which these nouns occurred (i.e. as subjects vs. objects, topics vs. focused elements) was done. Future research on TiD and other sign languages is needed to investigate the influence of factors such as definiteness, and information structure on expression of multiple entities, which have been shown to play a role in plural marking in many spoken languages.

\section{Conclusion}

This paper reports on a detailed descriptive and quantificational analysis of expression of multiple entities in TiD. We have found that TID does not exhibit morphological marking of plural on the noun. Instead, TiD signers appear to express multiple entities through a variety of devices, most of which involve spatial modification to reflect referent relations. The primary linguistic function of these devices, however, is not the expression of plurality, but rather the depiction of referent location, on the one hand, and predicate inflection, on the other hand. Information about referent plurality falls out as a result of the use of space in the visual-spatial modality. Thus, although TiD employs several devices through which referent plurality can be expressed, we conclude that TiD does not have explicit, productive plural marking devices, in contrast to what has been claimed by Kubuş (2008).

These spatial devices are common across sign languages, and we have argued that we expect expression of multiple entities in the visual-gestural modality to primarily take this form, instead of being expressed morphologically on the noun through a dedicated, productive strategy. Our findings for TiD confirm this prediction. The visual-spatial modality easily affords expression of multiple entities as a by-product of the iconically-motivated spatial marking of referent relations, but does not facilitate systematic or obligatory morphological marking on the noun. As we have seen, the one form of morphological plural marking that does exist in sign languages, i.e. noun reduplication, is not obligatory and is phonologically or contextually blocked in many environments.

Given the affordances and constraints of the visual-gestural modality, we expect the patterns we have found in TiD to be generalizable across sign languages. Under this analysis, we expect explicit plural marking devices to be scarce and severely restricted across sign languages, in contrast to the diversity of plural marking structures found in spoken languages. Moreover, across sign languages, we expect to find iconic, spatially-motivated structures that make use of the principle of multiple-referent-to-multiple-location mapping, and to thus similarly express referent plurality in predicates primarily expressing relations between referents through localization or inflection. However, it remains to be seen whether the relative youth of sign languages plays a role in the modality-specific similarity of sign languages in this domain. Thus, in the future, as sign languages continue to develop and mature, more (and varied) specific plural markers, not observed currently, may well emerge in sign languages.

\section{Notational conventions}

Signs in the cited examples are labeled in English with capital letters (e.g. TOWN). If two morphemes are combined within one sign, their glosses are divided by hyphens (e.g. 3-DAY). Subscripts (e.g. $T O W N_{\varnothing}$ ) signal that the sign is articulated at a particular location in space. Occurrence of a classifier within a sign is represented with 'CL', plus the entity it classifies or the entity class in subscript (e.g. $C L_{\text {BICYCLE}}, C L_{\text {round }}$ ). Two glosses connected by a ${ }^{\wedge}$ indicate a compound.

The examples from our TiD data are represented with photo stills. They are glossed according to the Leipzig Glossing Rules (http://www.eva.mpg.de/lingua/resources/glossing-rules.php, last consulted June 1, 2012). Where relevant, LH and RH stand for 'left hand' and 'right hand'. Subscripts indicate the specific location of a referent in space (in localization predicates) or reflect the location of the referent with which it agrees (in inflected predicates). The gloss 'non1.SG' indicates a non-first singular pronoun.

\section{Acknowledgements}

This research was funded by a Dutch Science Foundation (NWO) VIDI grant (\#276-70-009) to the last author and the Max Planck Institute for Psycholinguistics. We thank Marloes van der Goot and Menno Jonker for technical assistance and archiving of the data, Hasan Hüseyin Korkmaz for TiD glossing, and İzmir Sağırları Koruma ve Kalkındırma Derneği, İzmir, Hatay, Turkey (İzmir Deaf Association) and its members for their help in conducting this study. We also thank the three Lingua reviewers for their valuable comments. We are grateful to Beyza Sümer, Hükümran Sümer, Sevinç Lamia Yücealtay, and especially to Okan Kubuş for helpful discussions about the data.

The examples from LIS in Figs. 1 and 5 are reprinted from Lingua 98, Pizzuto, E. and Corazza, S., Noun morphology in Italian Sign Language, pp. 169-196, Copyright (1996), with permission from Elsevier. 
The DGS examples in Fig. 1a and 8b are reprinted from Linguistic Typology 10, Pfau, R. and Steinbach, M. Pluralization in Sign and Speech: A cross-modal typological study, pp. 135-182, Copyright (2006), with permission of Mouton de Gruyter.

The ASL examples in Fig. 2a are from 'Exploitation of morphological possibilities in signed languages. Comparison of American Sign Language with English.' Fernald, T.B., Napoli, D.J., In: Sign Language \& Linguistics 3, Copyright (2000), pp. 3-58. Reprinted with kind permission of John Benjamins Publishing Company, Amsterdam/Philadelphia. [www. benjamins.com].

The DGS signs in Fig. 2b are from 'Allgemeines Gebärdenlexikon des Instituts für Deutsche Gebärdensprache und Kommunikation Gehörloser der Universität Hamburg', with kind permission of the publishers.

The BSL examples in Fig. 3 are reprinted from 'Sign Language. The study of deaf people and their language', Kyle, J., and Woll, B., Copyright (1985), with friendly permission of the illustrator, Bernard Quinn (bernardq@learning-difference. org.uk).

The BSL examples in Fig. 6 are reprinted from 'Chapter 11. Pronouns.' Cormier, K. In: Sign language: An international handbook. Pfau, R., Steinbach, M., and Woll, B. (Eds.), Copyright (2012). Reprinted with kind permission of Mouton de Gruyter, Berlin.

The BSL examples in Fig. 9 are reprinted from 'The linguistics of British Sign Language', Sutton-Spence, R., and Woll, B., Copyright (1999), with kind permission of Cambridge University Press.

\section{References}

Aikhenvald, A., 2000. Classifiers: A Typology of Noun Categorization Devices. Oxford University Press, Oxford.

Arık, E., 2008. Locative constructions in Turkish Sign Language (TID). In: de Quadros, R.M. (Ed.), Sign Languages: Spinning and Unraveling the Past, Present and Future. TISLR9, Forty-five Papers and Three Posters from the 9th Theoretical Issues in Sign Language Research Conference. Editora Arara Azul Petrópolis, RJ, Brazil, pp. 319-352.

Arık, E., 2010. Describing motion events in sign languages. Poznán Studies in Contemporary Linguistics 46, 367-390.

Aronoff, M., Meir, I., Sandler, W., 2005. The paradox of sign language morphology. Language 81, 301-344.

Boğaziçi Üniversitesi Türk İşaret Dili (TiD) Kaynak Sitesi, 2008-2011. Boğaziçi Üniversitesi TiD Resourse Website, http://www.cmpe.boun.edu.tr/ $\mathrm{tid} /$.

Boster, C.T., 1996. On the quantifier-noun phrase split in American Sign Language and the structure of quantified phrases. In: Edmondson, W.H., Wilbur, R.B. (Eds.), International Review of Sign Linguistics, vol. 1. Lawrence Erlbaum Associates, Mahwah, NJ.

Corbett, G., 2000. Number. Cambridge University Press, Cambridge.

Corbett, G., 2007. Canonical typology, suppletion and possible words. Language 83, 8-42.

Cormier, K., 2012. Pronouns. In: Pfau, R., Steinbach, M., Woll, B. (Eds.), Sign Language: An International Handbook. Mouton de Gruyter, Berlin.

Crasborn, O., Van der Kooij, E., Ros, J., 2012. On the weight of phrase-final prosodic words in a sign language. In: Brentari, D., Wilbur, R.B. (Eds.), New Methodologies in Sign Language Phonology: Papers from TISLR 10: Special issue of Sign Language \& Linguistics 15, vol. 1, pp. 11-38.

De Beuzeville, L., Johnston, T., Schembri, A., 2009. The use of space with indicating verbs in Australian Sign Language: a corpus-based investigation. Sign Language \& Linguistics 12, 53-82.

Deen, Kamil Ud., 2005. The Acquisition of Swahili. John Benjamins Publishing Company, Amsterdam/Philadelphia.

Dryer, M., 2011. Coding of nominal plurality. In: Dryer, Matthew, S., Haspelmath, M. (Eds.), The World Atlas of Language Structures Online. Max Planck Digital Library, Munich, (Chapter 33) http://wals.info/chapter/33 (accessed on 21.05.12).

Engberg-Pedersen, E., 1993. Space in Danish Sign Language: The Semantics and Morphosyntax of the Use of Space in a Visual Language. Signum, Hamburg.

Erlenkamp, S., 2000. Syntaktische Kategorien und Lexikalische Klassen. Typologische Aspekte der Deutschen Gebärdensprache. Lincom, Munich.

Evans, N., Levinson, S., 2009. The myth of language universals: language diversity and its importance for cognitive science. Behavioral and Brain Sciences 32, 429-492.

Fernald, T.B., Napoli, D.J., 2000. Expoitation of morphological possibilities in signed languages: comparison of American Sign Language with English. Sign Language \& Linguistics 3, 3-58.

Frishberg, N., Gough, B., 2000. Morphology in American Sign Language. Sign Language \& Linguistics 3, 103-131, (Original working paper: 1973).

Gökgöz, K., 2011. Negation in Turkish Sign Language: the syntax of nonmanual markers. Sign Language \& Linguistics 14, 49-75.

Gordon, L., 1986. Maricopa Morphology and Syntax. University of California Press.

Green, T., 1992. Covert Clause structure in the Miskitu noun phrase. Unpublished paper. Massachusetts Institute of Technology, Cambridge, MA.

Grinevald, C., 2000. A morphosyntactic typology of classifiers. In: Senft, G. (Ed.), Systems of Nominal Classification. Cambridge University Press, Cambridge, pp. 50-92.

Haspelmath, M., 2011. Occurrence of nominal plurality. In: Dryer, Matthew, S., Haspelmath, M. (Eds.), The World Atlas of Language Structures Online. Max Planck Digital Library, Munich, (Chapter 34) http://wals.info/chapter/34 (accessed on 10.05.12).

Heyerick, I., van Braekevelt, M. Rijckaert, J., de Weerdt, D., van Herreweghe, M., Vermeerbergen, M., 2011. Meervoud in Vlaamse Gebarentaal. Onderzoeksrapport, 2011. Plural in Flemish Sign Language. Research Report, 2011. Unpublished manuscript, Vlaams GebarentaalCentrum, Antwerpen. Available at: http://www.vgtc.be/sites/default/files/2011_meervoud_in_vgt.pdf.

Heyerick, I., Vermeerbergen, M., Van Herreweghe, M. Plurality in Flemish Sign Language, in preparation.

Institut für Deutsche Gebärdensprache und Kommunikation Gehörloser der Universität Hamburg, 2004. Allgemeines Gebärdenlexikon. http:// www.sign-lang.uni-hamburg.de/alex/ (last consulted 11.05.11). 
Johnston, T., Vermeerbergen, M., Schembri, A., Leeson, L., 2007. Real data are messy: considering cross-linguistic analysis of constituent ordering in Australian Sign Language (Auslan), Vlaamse Gebarentaal (VGT) and Irish sign language (ISL). In: Perniss, P., Pfau, R., Steinbach, M. (Eds.), Proceedings of the Workshop on Sign Languages: A Cross-linguistic Perspective, Mainz, Germany, March 25-27, 2004. Mouton de Gruyter, Berlin, pp. 163-205.

Key, H., 1967. Morphology of Cayuvava. Janua Linguarum, Series Practica 53. Mouton, The Hague.

Klima, E., Bellugi, U., 1979. The Signs of Language. Harvard University Press, Cambridge, MA.

Kubuş, O., 2008. An analysis of Turkish Sign Language (TID) phonology and morphology. MA Thesis. The Middle East Technical University, Ankara.

Kutsch Lojenga, C., 1994. Ngiti: a central Sudanic language of Zaire. Nilo-Saharan, vol. 9. Rüdiger Köppe, Köln.

Kyle, J., Woll, B., 1985. Sign Language: The Study of Deaf People and their Language. University of Cambridge Press, Cambridge.

Lakoff, G., Johnson, M., 1980. Metaphors We Live By. University of Chicago Press, Chicago.

Leeding, V., 1989. Anindilyakwa Phonology and Morphology. PhD Dissertation. University of Sydney.

Liddell, S.K., 1996. Numeral incorporating roots \& non-incorporating prefixes in American Sign Language. Sign Language Studies 92, 201-226.

Liddell, S.K., 1998. Grounded blends, gestures and conceptual shifts. Cognitive Linguistics 9, 283-314.

Liddell, S.K., Johnson, R.E., 1986. American Sign Language compound formation processes, lexicalization, and phonological remnants. Natural Language \& Linguistic Theory 4, 445-513.

Lillo-Martin, D., Klima, E., 1990. Pointing out differences: ASL pronouns in syntactic theory. In: Fischer, S.D., Siple, E. (Eds.), Theoretical Issues in Sign Language Research. University of Chicago Press, Chicago (IL), pp. 191-210.

Mather, S., Winston, E., 1998. Spatial mapping and involvement in ASL storytelling. In: Lucas, C. (Ed.), Pinky Extension and Eye Gaze: Language Use in Deaf Communities. Gallaudet University Press, Washington, DC, pp. 170-182.

Mathur, G., Rathman, C., 2009. Constraints on two types of nonconcatenative morphology in signed languages. Ms. Available at: http://esslli2009. labri.fr/documents/08\%20MathurRathmann\%20ESSLLI\%202009.pdf.

Mathur, G., Rathman, C., 2010. Two types of nonconcatenative morphology in sign languages. In: Mathur, G., Napoli, D.J. (Eds.), Deaf Around the World: The Impact of Language. Oxford University Press, Oxford, pp. 54-82.

McBurney, S.L., 2002. Pronominal reference in signed and spoken language: are grammatical categories modality-dependent? In: Meier, R., Cormier, K., Quinto-Pozos, D. (Eds.), Modality and Structure in Signed and Spoken Languages. Cambridge University Press, Cambridge, pp. 329-369.

Meier, R.P., 2002. Why different? Why the same? Modality and structure in signed and spoken languages. In: Meier, R.P., Cormier, K., QuintoPozos, D. (Eds.), Modality and Structure in Signed and Spoken Languages. Cambridge University Press, Cambridge, pp. 1-27.

Meir, I., 2001. Verb classifiers as noun incorporation in Israeli Sign Language. In: Booij, G., Van Marle, J. (Eds.), Yearbook of Morphology 1999. Kluwer Academic Publishers, Dordrecht, pp. 299-319.

Namir, L., Schlesinger, I.M., 1978. The grammar of sign language. In: Schlesinger, I.M., Namir, L. (Eds.), Sign Language of the Deaf: Psychological, Linguistic, and Sociological Perspectives. Academic Press, New York/San Francisco/London, pp. 97-140.

Nespor, M., Sandler, W., 1999. Prosody in Israeli Sign Language. Language and Speech 42, 143-176.

Nijhof, S., Zwitserlood, I., 1999. Pluralization in Sign Language of the Netherlands (NGT). In: Don, J., Sanders, T. (Eds.), OTS Yearbook 19981999. UiL OTS, Utrecht, pp. 58-78.

Nyst, V., 2007 A descriptive analysis of Adamorobe Sign Language (Ghana). PhD Dissertation. Netherlands Graduate School of Linguistics (LOT), Utrecht.

Özyürek, A., Perniss, P.M., 2011. Event representations in signed languages. In: Bohnemeyer, J., Pederson, E. (Eds.), Event Representations in Language and Cognition. Cambridge University Press, New York, pp. 84-107.

Özyürek, A., Illkbaşaran, D., Arık, E., 2004. Türk İşaret Dili/Turkish Sign Language. http://turkisaretdili.ku.edu.tr (accessed 15.05.11).

Özyürek, A., Zwitserlood, I., Perniss, P., 2010. Locative expressions in signed languages: a view from Turkish Sign Language (TiD). Linguistics 48, 1111-1145.

Padden, C., 1988. Interaction of Morphology and Syntax in American Sign Language. Garland, New York.

Padden, C., Perlmutter, D., 1987. American Sign Language and the architecture of phonological theory. Natural Language \& Linguistic Theory 5 , 335-375.

Perlmutter, D., 1992. Syllable weight in American Sign Language. Paper presented at TISLR7, Amsterdam.

Perniss, P., 2001. Numerus und Quantifikation in der Deutschen Gebärdensprache (Numerals and Quantification in German Sign Language.) MA Thesis, University of Cologne.

Perniss, P., 2007. Space and iconicity in German Sign Language (DGS). Ph.D. Dissertation, Radboud University Nijmegen.

Perniss, P., Özyürek, A., 2008. Constructing action and locating referents: a comparison of German and Turkish Sign Language narratives. In: Quer, J. (Ed.), Signs of the Time. Selected papers from TISLR 8. Signum Press, Hamburg.

Perniss, P., Zwitserlood, I., Özyürek, A., 2011. Does space structure spatial language? Linguistic encoding of space in sign languages. In: Carlson, L., Hölscher, C., Shipley, T. (Eds.), Proceedings of the 33rd annual conference of the Cognitive Science Society. Cognitive Science Society, Austin, TX.

Pfau, R., Steinbach, M., 2006. Pluralization in sign and speech: a cross-modal typological study. Linguistic Typology 10, 135-182.

Pizzuto, E., Corazza, S., 1996. Noun morphology in Italian Sign Language (LIS). Lingua 98, 169-196.

Pyers, J.E., 2006. Indicating the body: expression of body part terminology in American Sign Language. Language Sciences 28, 280-303.

Roberts, J., 1987. Amele. Croom Helm, London.

Rubino, C., 2001. Ilocano, Waray, Pangasinan (three grammar sketches). In: Garry, J., Rubino, C. (Eds.), Encyclopedia of the World's Languages, Past and Present. H.W. Wilson, New York, pp. 539-542.

Sandler, W., 1996. Representing handshapes. In: Edmundsen, E.H., Wilbur, R. (Eds.), International Review of Sign Linguistics. Lawrence Erlbaum Associates, Mahwah, NJ, pp. 115-158.

Sandler, W., 1999. The medium and the message. Prosodic interpretation of linguistic content in Israeli Sign Language. Sign Language \& Linguistics 2, 187-215.

Sandler, W., Lillo-Martin, D., 2006. Sign Language and Linguistic Universals. Cambridge University Press, Cambridge. 
Schembri, A., 2003. Rethinking 'Classifiers' in signed languages. In: Emmorey, K. (Ed.), Perspectives on Classifiers in Sign Language. Lawrence Erlbaum Associates, Mahwah, NJ, pp. 3-34.

Schembri, A., McKee, D., McKee, R., Pivac, S., Johnston, T., Goswell, D., 2009. Phonological variation and change in Australian and New Zealand Sign Languages: the location variable. Language Variation and Change 21, 193-231.

Schmaling, C., 2000. Maganar Hannu: Language of the Hands: A Descriptive Analysis of Hausa Sign Language. Signum, Hamburg.

Sevinç, A., 2006. Grammatical Relations and Word Order in Turkish Sign Language (TiD). MA Thesis. The Middle East Technical University, Ankara.

Slobin, D.I., Hoiting, N., Kuntze, M., Lindert, R., Weinberg, A., Pyers, J., Anthony, M., Biederman, Y., Thumann, H., 2003. A cognitive/functional perspective on the acquisition of 'Classifiers'. In: Emmorey, K. (Ed.), Perspectives on Classifiers in Signed Languages. Lawrence Erlbaum Associates, Mahwah, NJ, pp. 271-298.

Sneddon, J., 1996. Indonesian: A Comprehensive Grammar. Routledge, London.

Stavans, A., 1996. One, two or more: the expression of number in Israeli Sign Language. In: Edmondson, W., Wilbur, R. (Eds.), International Review of Sign Linguistics, vol. 1. Lawrence Erlbaum Associates, Mahwah, NJ, pp. 95-114.

Supalla, T., 1982. Structure and acquisition of verbs of motion and location in American Sign Language. Ph.D. Thesis. UCSD, San Diego.

Supalla, T., 1986. The classifier system in American Sign Language. In: Craig, C. (Ed.), Noun Classes and Categorization. John Benjamins, Amsterdam, pp. 181-214.

Sutton-Spence, R., Woll, B., 1999. The Linguistics of British Sign Language. An Introduction. Cambridge University Press, Cambridge.

Tyrone, M., Mauk, C., 2010. Sign lowering and phonetic reduction in American Sign Language. Journal of Phonetics 38, 317-328.

Van der Kooij, E., 1997. Contact: a phonological or a phonetic feature of signs? In: Coerts, J.A., De Hoop, H. (Eds.), Linguistics in the Netherlands, vol. 14. John Benjamins, Amsterdam, pp. 109-122.

Van der Kooij, E., Crasborn, O., 2008. Syllables and the word-prosodic system in Sign Language of the Netherlands. Lingua 118, $1307-1327$.

Van der Kooij, E., Crasborn, O., Emmerik, W., 2006. Explaining prosodic body leans in Sign Language of the Netherlands: pragmatics required. Journal of Pragmatics 38, 1598-1614.

Van Hoek, K. 1992. Paths Through Conceptual Structure: Constraints on Pronominal Anaphora. Ph.D. Dissertation. University of San Diego, Linguistics Department.

Wilbur, R., 1987. American Sign Language: Linguistic and Applied Dimensions. Little Brown \& Co., Boston.

Wilbur, R., 2005. A reanalysis of reduplication in American Sign Language. In: Hurch, B. (Ed.), Studies on Reduplication. Mouton de Gruyter, Berlin, pp. 595-623.

Wilbur, R., Schick, B.S., 1987. The effects of linguistic stress on sign movement in ASL. Language and Speech 30, $301-323$.

Zeshan, U., 2000. Sign Language in Indo-Pakistan: A Description of a Signed Language. John Benjamins Publishing Company, Philadelphia/ Amsterdam.

Zeshan, U., 2002. Sign language in Turkey: the story of a hidden language. Turkic Languages 6, 229-274.

Zeshan, U., 2003. Aspects of Türk Işaret Dili (Turkish Sign Language). Sign Language and Linguistics 6, 43-75.

Zeshan, U., 2006. Interrogative and Negative Constructions in Sign Languages. Ishara Press, Nijmegen.

Zwitserlood, I., 2003. Classifying hand configurations in Nederlandse Gebarentaal (Sign Language of the Netherlands). PhD. Dissertation. Netherlands Graduate School of Linguistics (LOT), Utrecht.

Zwitserlood, I., 2012. Classifiers. In: Pfau, R., Steinbach, M., Woll, B. (Eds.), Sign Language: An International Handbook. Mouton de Gruyter, Berlin. 